La guerre de 1856 n'aura pas lieu. Ein 'Scheinkriegsrat Napoleons III.

Sechs Wochen vor Zusammentritt des Pariser Friedenskongresses hatte in den Tuilerien ein Gremium getagt, das als $>$ Kriegskongreß ${ }^{1}$ apostrophiert wurde. Es vereinigte hochrangige Militärs, Diplomaten und Politiker jener drei Mächte, die, Verbündete des Osmanischen Reiches, gegen Rußland im Krieg standen: England, Frankreich, Sardinien. Als Ergebnis der vier Sitzungen vom 10., 12., 14. und 17. Januar 1856 legte Napoleon III., der den Vorsitz geführt hatte, am 20. Januar einen Feldzugsplan vor, dem das britische Kabinett nach einigem Hin und Her zustimmte. Er sah als Hauptkriegstheater die Krim vor, während in der Ostsee mit eher bescheidenen, rein maritimen Kräften und gegen ein einziges Ziel operiert werden sollte, gegen Kronstadt.

Als der "great Council of War « ${ }^{2}$ seine Arbeit aufnahm, erwartete Europa in fieberhafter Spannung Rußlands Antwort auf die ihm von Österreich in ultimativer Form vorgelegten Friedensbedingungen der Verbündeten. Indem Petersburg sich ihnen ohne Abstriche und Vorbehalte unterwarf, setzte es den Schlußpunkt unter die Pariser Beratungen ${ }^{3}$. Mit der Einschüchterung des Zarenreichs ${ }^{4}$, dem sie den Kriegswillen seiner Gegner demonstrierten, hatten sie einen nicht unwichtigen Beitrag zum Friedensprozeß geleistet. Eine weitere Funktion des Kriegsrats - dem englischen Partner die Überzeugung zu vermitteln, daß auf Frankreichs militärische Solidarität weiterhin zu zählen sei - ging nach dem

1 Vaillant an Pélissier, 20. 11. 1855, in: Camille Rousset, Histoire de la Guerre de Crimée, vol. 2, 2. éd., Paris 1878, S. 427: »une espèce de congrès«; Cowley an Clarendon, 6. 11. 1855, Akten zur Geschichte des Krimkriegs (AGKK). Hrsg. von Winfried Baumgart. Serie III: Englische Akten zur Geschichte des Krimkriegs, Bd 4: 10. 9. 1855 bis 23. 7. 1856. Bearb. von Winfried Baumgart unter Mitw. von Wolfgang Elz, München, Wien 1988, Nr. 142: »military congress «. - Zum ganzen vgl. Winfried Baumgart, Ein Kriegsrat Napoleons III. Englisch-französische Feldzugspläne gegen Rußland 1855/56, in: Festschrift für Eberhard Kessel zum 75. Geburtstag, hrsg. von Heinz Duchhardt und Manfred Schlenke, München 1982, S. 212-235.

2 Cowley an Clarendon, 6. 11. 1855, AGKK, III, 4 (wie Anm. 1), Nr. 142.

3 Vgl. Aufzeichnung J. Napoleons, 16. [!] 1. 1856, Archives Nationales (AN), 400 AP, 119, Nr. 6.

4 Nesselrode berief sich während des Kronrats vom 15. 1. 1856 nicht zuletzt auf die vermuteten Beschlüsse des Kriegsrats; u. a. rechnete er mit einem französischen Angriff auf Bessarabien, vgl. Winfried Baumgart, Der Friede von Paris 1856. Studien zum Verhältnis von Kriegführung, Politik und Friedensbewahrung, München, Wien 1972, S. 114. Daß die führenden 'Frontgenerälec, namentlich Pélissier, in Paris fehlten, hatte also keineswegs den von Eingeweihten befürchteten Effekt gehabt: »Cette manifestation [...] ne sera prise au sérieux par personne, à commencer probablement, par ceux qui en font partie. - Cela me donnerait presque envie de croire à la paix. « Chimay an Ernst II., 12. 1. 1856, Staatsarchiv Coburg (StAC), LA A 7181, f. 28. 
20. Januar auf den napoleonischen Feldzugsplan ${ }^{5}$ über, zu dessen Verwirklichung Paris tatsächlich Anstalten traf.

Andererseits wurde der Abzug französischer Truppen aus dem Orient unvermindert fortgesetzt. War während des Kriegsrats ihre Zahl auf 154000 beziffert worden, so betrug sie Anfang Februar noch 129 000, nach englischen Angaben sogar nur $96000 \mathrm{Mann}^{6}$. Es sind also um die 1000 Mann pro Tag nach Frankreich zurückverlegt worden; eher mehr, da anzunehmen ist, daß der Truppenabbau teilweise als Truppenaustausch kaschiert wurde. - So war es schon im Herbst 1855 geschehen. Damals waren bis zu 20000 Mann, darunter die Garde und die vier dienstältesten Regimenter, ins Mutterland eingeschifft worden; zwei neue Divisionen (zusammen 16000 Mann) hatten den Platz der Veteranen eingenommen. In der Armee hatte man dies als politisches Signal verstanden. Man zeige Flagge auf der Krim, aber »sans y consacrer de vieilles troupes, qui doivent rester disponibles pour les éventualités de l'Allemagne ${ }^{7}$.

\section{Große Erwartungen}

Auf der Krim und selbst in Südrußland gab es nach dem Fall Sevastopol's kein lohnendes, politisch sinnvolles Ziel für die alliierten Streitkräfte mehr. Wozu die Krim noch erobern, wenn ihre Rückgabe an Rußland praktisch schon beschlossene Sache war? Und die Einnahme des unbestreitbar bedeutenden Waffenplatzes Nikolaev, die den französischen Oberkommandierenden Aimable-Jean Pélissier schwieriger dünkte als jene Sevastopol's - würde sie das Zarenreich wirklich in die Knie zwingen ${ }^{8}$ Vom Standpunkt Frankreichs aus, das bisher die Hauptlast des Krieges getragen hatte, sprach alles dafür, ihm ein anderes Theater anzuweisen, die taurische Halbinsel hingegen zur Nebenbühne herabzustufen: »Son or et son sang ne seront plus attirés vers cette funeste Crimée par un courant fatal et irrésistible ${ }^{9}$ " In London fand die Anregung, sie weitgehend zu räumen, zwar kein Gehör; Napoleons Vorschlag, von einer neuerlichen Kampagne an dieser Front Abstand zu nehmen, kam aber den Vorstellungen der britischen Staats-

5 Vgl. Denkschrift Napoleons, 20. 1. 1856, gedruckte Fassung in Public Record Office (PRO), WO 33/2 B, S. 53-56; verfilmt in: The Oriental Question 1840-1900. Files from the Royal Archives Windsor Castle. Reel XIX, Frederick, Md. 1984, G 43/89. - Vaillant befahl am 4. 2. 1856 die Besetzung von Sak »comme base des opérations futures «, Service Historique de l'Armée de Terre (SHAT), G 1, 38, Nr. 3. Am 23. Februar mußte die Order wiederholt werden, so daß man in London argwöhnte, "that Pélissier will have done nothing", Clarendon an Palmerston, 25. 2. 1856: AGKK, III, 4 (wie Anm. 1), Nr. 473; vgl. ebd., S. 795, Anm. 9.

6 Nachweis der Zahlenangaben in Baumgart, Kriegsrat (wie Anm. 1), S. 222.

7 Espinasse an Napoleon, 6. 12. 1855, AN (wie Anm. 3), 400 AP, 55, Nr. 4; vgl. Ministerkonferenz, 27. 11. 1855, AKGG. Serie I: Österreichische Akten zur Geschichte des Krimkriegs, Bd 3: 10. 9. 1855 bis 24. 5. 1856. Bearb. von Winfried Baumgart, München, Wien 1979, Nr. 49.

8 Vgl. Espinasse an Napoleon, 6. 12. 1855, AN (wie Anm. 3), 400 AP, 55, Nr. 4; Thouvenel an Walewski, 27. 9. 1855, SHAT (wie Anm. 5), G 1, 29; Pélissier an Vaillant, 24. 10. und 19. 11. 1855, Rousset, Histoire (wie Anm. 1), S. 421, 425-427 bzw. AGKK, III, 4 (wie Anm. 1), S. 256, Anm. 6, 386, Anm. 2.

9 Gutachten J. Napoleons, 17. 1. 1856, AN (wie Anm. 3), 400 AP, 55, Nr. 2. 
männer durchaus entgegen. ${ }^{10}$ Sie sahen vor, den russischen Koloß von der Ostküste des Schwarzen Meeres und von der Ostsee her in die Zange zu nehmen, wobei man als Hauptkriegsschauplatz zunächst Georgien und Zirkassien gewählt, mit Rücksicht auf Frankreichs unübersehbare Abneigung gegen eine Kaukasus-Expedition schließlich jedoch dem Baltikum Priorität eingeräumt hatte ${ }^{11}$. Alles schien in den Wochen vor Zusammentritt des Kriegsrats auf einen Stoß ins Herz, gegen St. Petersburg, zuzulaufen: Der Bündnisvertrag vom 21. November 1855 zwischen den Seemächten und Schweden, der Abzug französischer Kerntruppen aus dem Orient, die gewaltige Aufrüstung der britischen Marine, sogar die Taktlosigkeit, beim >Kriegskongreß< ausgerechnet auf einen osmanischen Repräsentanten zu verzichten ${ }^{12}$. Prinz Napoleon verlieh der erwarteten Marschrichtung treffend Ausdruck, als er im Rubrum seines ersten Sitzungsprotokolls ${ }^{13}$ »campagne d'Orient « abänderte in »campagne contre la Russie«. Für die Hoffnungen respektive Befürchtungen des Mannes auf der Straße wiederum dürfen die Prophezeiungen Friedrich Wilhelms IV. gerade deshalb als repräsentativ gelten, weil der Hohenzoller sein Schlachtenpanorama bewußt mit grellen Farben gestaltete $^{14}$.

Was zuallerletzt erwartet wurde, war ein weiterer Feldzug auf der Krim. Der Kaiser der Franzosen hätte ihn am liebsten völlig von der Tagesordnung gestrichen und gab dem britischen Botschafter zu verstehen, er werde die Auswahl der Kriegsratsteilnehmer so treffen, daß ein französisches Votum zugunsten der Ostsee-Expedition nicht zweifelhaft sein könne ${ }^{15}$. Den >Krimkrieg < wollte er nur unter einer Bedingung fortsetzen: wenn die Beratungen zu dem Ergebnis führten, es sei damit »etwas Bedeutendes ${ }^{16}$ auszurichten.

10 Vgl. Persigny an Napoleon, 30. 10. 1855, Archives du Ministère des Affaires Etrangères (AMAE), PA Walewski, 24, f. 50-54,57-62 und 19. 12. 1855, Bodleian Library Oxford (BLO), Clarendon Dep., c. 35, f. 541-543.

11 Vgl. Palmerston an Clarendon, 22. und 23. 11. 1855, AGKK, III, 4 (wie Anm. 1), Nr. 186, 192; Clarendon an Cowley, 16. und 23. 11. 1855, ebd., Nr. 161, 196; Clarendon an Stratford, 19. 11. 1855, ebd., Nr. 171; Clarendon an Seymour, 18. 12. 1855, ebd., Nr. 276; Clarendon an Magenis, 8. 12. 1855, ebd., Nr. 248; Persigny an Napoleon, 19. 12. 1855, BLO (wie Anm. 10), Clarendon Dep., c. 35, f. 541-543.

12 Vgl. Clarendon an Stratford, 28. 12. 1855, AGKK, III, 4 (wie Anm. 1), Nr. 295; Thouvenel an Walewski, 23. 12. 1855, AMAE (wie Anm. 10), CP Turquie, 323, f. 191; Walewski an Napoleon, 25. 12. 1855, Familienarchiv Walewski, C 1, p. 55.

13 Vom 10. 1. 1856, AN (wie Anm. 3), 400 AP, 119, Nr. 6.

14 »[...] les opérations de 100000 hommes (ou plutôt du double) sur les deux rives du golphe, l'insurrection arrêtée de la Pologne, les dangers très-réels de Cronstadt, de la flotte et surtout de St. Pétersbourg même." Friedrich Wilhelm IV. an Alexander II., 6. 1. 1856, in: Kurt Borries, Preußen im Krimkrieg (1853-1856), Stuttgart 1930, Anlage 28; vgl. Friedrich Wilhelm IV. an Manteuffel, 7. 1. 1856, AGKK. Serie II: Preußische Akten zur Geschichte des Krimkriegs, Bd 2: 9. 8. 1854 bis 15. 4. 1856. Bearb. v. Winfried Baumgart, Wolfgang Elz und Werner Zürrer, München 1990, Nr. 372.

15 Vgl. Cowley an Clarendon, 4. 12. 1855, AGKK, III, 4 (wie Anm. 1), Nr. 236.

16 Denkschrift Napoleons, 20. 1. 1856, PRO (wie Anm. 5), WO 33/2 B, S. 53; vgl. auch Cowley an Clarendon, 10. 12. 1855, Le Relazioni diplomatiche fra la Gran Bretagna e il Regno di Sardegna. Ed. Istituto Storico Italiano [...]. Serie III, vol. 5: 11. 1. 1855-30. 12. 1856. A cura di Federico Curato, Roma 1969, Nr. 126. - Die Bezeichnung »guerre de Crimée« (anstelle des vorherrschenden "guerre de'Orient " bzw. "campagne de Crimée«) z. B. in Napoleon an Palmerston, 26. 2. 1855, Southampton University Library (SUL), Palmerston Papers, GC/NA 98. 
Dreieinhalb Systeme

Vor dem Hintergrund des anglo-französischen Tauziehens über die Aufnahme des österreichischen Friedensschritts hatte Napoleon am 22. November 1855 ein Handschreiben an die englische Königin gerichtet, worin er unmißverständlich erklärte, Frankreichs Einsatz werde fortan davon abhängen, um welche Ziele es gehe, ob um »mikroskopische Vorteile ${ }^{17}$ oder um 'große Politik<. Letztere sah er durch das österreichische Ultimatum verkörpert: Solange der Kreis der Conditiones sine quibus non nicht um Detailfragen erweitert wurde, die eigentlich in die Friedensverhandlungen gehörten, stellte Petersburgs Ablehnung einen legitimen Grund dar, den Krieg im bisherigen oder noch größeren Maßstab fortzusetzen. - Für erstere standen, späteren Ausführungen des Kaisers zufolge, auch solche Forderungen, die, anders als die ursprünglichen Vier Punkte, eher partikularen

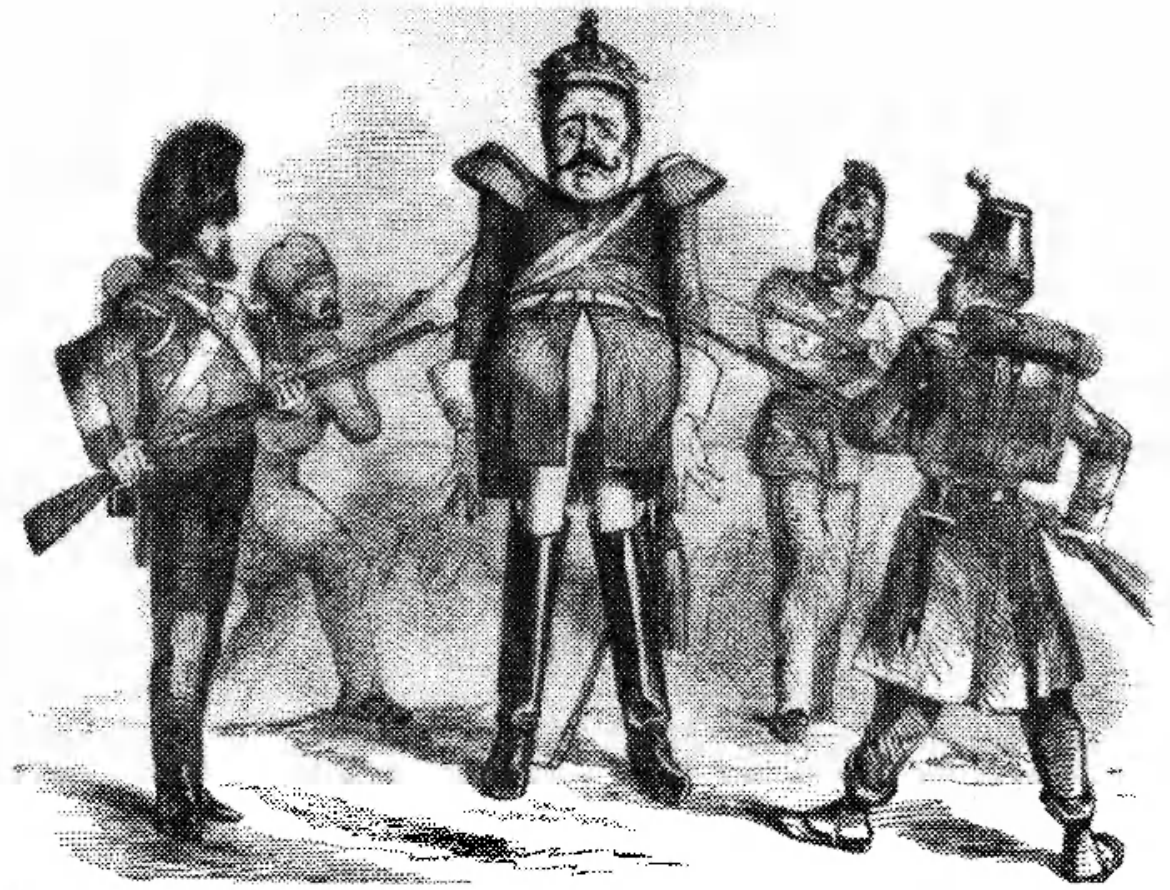

Der Kriegsrat schien der erste Schritt dazu, dem Zaren das westliche Friedensprogramm mittels eines Concert europeen en armes aufzuzwingen. Preußens Platz im Kreis der Großmächte hat die Türkei eingenommen

17 Napoleon an Victoria, 22. 11. 1855, in: Theodore Martin, The Life of His Royal Highness the Prince Consort. Vol. 3, 6. ed., London 1878, S. 526; vgl. auch Napoleon an Persigny, 13. 12. 1855, BLO (wie Anm. 10), Clarendon Dep., c. 35, f. 453 f. bzw. The Paris Embassy during the Second Empire. Selections from the Papers of Henry Richard Charles Wellesley First Earl Cowley [...] 1852-1867. Ed. by Frederick Arthur Wellesley, London 1928 , S. 88. 
denn europäischen Interessen zu dienen schienen. Das galt in erster Linie für die >österreichische Gebietsforderung an Rußland ${ }^{18}$ : „Compromettre les finances de la France, répandre ses trésors et son sang et pourquoi: pour obtenir quelques landes de la Bessarabie!!! « Es konnte aber mit gleichem Recht von den senglischen $<$ Spezialbedingungen, dem Fünften Punkt, behauptet werden ${ }^{19}$.

Für den Fall, daß man auf eine 'Bezwingung ${ }^{20}$ des Zarenreichs verzichten würde, für die Napoleon Deutschlands Waffenhilfe als unabdingbar erachtete, legte er ein zweites System vor. Es propagierte eine intern längst von ihm favorisierte Idee $^{21}$, die Selbstbeschränkung der Seemächte auf einen Blockade- und Stellungskrieg, um den Gegner unter Druck zu halten und gleichzeitig die eigenen Kassen zu entlasten. - Das Beharren auf einem Kriegsgrund, der vor den Augen der Franzosen bestehen konnte ${ }^{22}$, und die Suche nach einem Ausweg aus der taurischen Materialschlacht sind zwei Seiten ein und derselben Medaille: Über das Frühjahr 1856 hinaus war die Kriegsfinanzierung nicht gesichert, eine neue Anleihe oder Steuererhöhungen ${ }^{23}$, und damit die Einschaltung des Corps législatif, unumgänglich.

Das dritte System war in eine prägnante Formel gefaßt: »Faire un appel à toutes les nationalités ${ }^{24}$ " Sie beschwor die Vision eines gesamteuropäischen und nach Mitteln wie Zielen revolutionären Krieges herauf, an dessen Ende Polen, Finnen, Magyaren, Italiener und Zirkassier aus ihren jeweiligen Völkerkerkern befreit sein würden. Ganz offensichtlich sollte diese Schilderung auf den eigentlichen Adressaten, das britische Kabinett, nicht werbend, sondern abschreckend wirken, also zugunsten des diplomatischen Schulterschlusses mit Wien. Warum sonst hätte Napoleon den Advocatus diaboli spielen sollen, indem er die >Gefährlichkeit ‘ und `Ungerechtigkeit ‘ der nationalrevolutionären Lösung betonte, ohne groß zu differenzieren? Ein Aufrollen der italienischen und vollends der ungarischen Frage war zweifellos nicht anders zu verwirklichen als gegen das verbündete Habsburgerreich - deshalb sungerecht ‘ und mit dem Risiko behaftet, daß die Geister von 1848 auch die Heilige Allianz ins Leben zurückriefen. Hingegen hätte die Eigenstaatlichkeit Finnlands und Zirkassiens im Außenministerium am Ballhausplatz genauso toleriert werden können wie die Selbständigkeit Belgiens und Griechenlands. Polen freilich war ein Grenzfall.

18 Die ursprünglichen Vier Punkte sind niedergelegt im Wiener Notenwechsel vom 8. 8. 1854, Text u.a. in: Aktenstücke zur orientalischen Frage, [...] zusammengestellt von Julius v. Jasmund, Bd 1, Berlin 1855, S. 465 f. Die Seemächte und Österreich hatten gefordert: 1. Ablösung des russischen Protektorats über die Donaufürstentümer durch eine Kollektivgarantie der Großmächte; 2. Freiheit der Donauschiffahrt gemäß den Prinzipien der Wiener Kongreßakte; 3. Revision der Meerengenkonvention von 1841 im Sinne des europäischen Gleichgewichts; 4 . Verzicht Rußlands auf die Schutzherrschaft über die Christen im Osmanischen Reich. - Außerdem hatten die Kriegführenden sich vorbehalten, diese Friedensbedingungen zu ändern und zu ergänzen. Der Fünfte Punkt des Ultimatums vom 16. 12. 1855 hatte diesen Anspruch erneuert, vgl. AGKK I, 3 (wie Anm. 7), Nr. 65. - Nachfolgendes Zitat: Napoleon an Victoria, 14. 1. 1856, The Letters of Queen Victoria. A Selection from Her Majesty's Correspondence between the Years 1837 and 1861. Ed. by Arthur Christopher Benson and Viscount Esher [Reginald B. Brett], vol. 3: 1854-1861, London 1908, S. 163.

19 Vgl. Hübner an Buol, 17. und 19. 1. 1856, AGKK, I, 3 (wie Anm. 7), Nr. 137, 145.

20 Napoleon an Victoria, 22. 11. 1855, Martin, Life (wie Anm. 17), S. 525.

21 Vgl. Persigny an Walewski, 26. 7. 1855, AMAE (wie Anm. 10), CP Angleterre, 701, f. 224-230 und 3. 8. 1855, AMAE (wie Anm. 10), PA Walewski, 24, f. 30.

22 Vgl. Napoleon an Victoria, 14. 1. 1856, Victoria, Letters (wie Anm. 18), S. 163.

23 Vgl. Cowley an Clarendon, 28. 10. 1855, AGKK, III, 4 (wie Anm. 1), Nr. 128.

24 Napoleon an Victoria, 22. 11. 1855, Martin, Life (wie Anm. 17), S. 525. 
Gleichsam unter der Hand entwickelte der Kaiser noch ein viertes System. Er verwies auf die Möglichkeit, sich neue Kriegsziele zu setzen, die der Mühe wirklich wert seien, nämlich die "Umarbeitung der europäischen Landkarte“ in Angriff zu nehmen. Jetzt aber sprach er, anders als noch im Zusammenhang mit dem >Appell an die Nationalitäten', statt von »Unabhängigkeit« auf einmal von Annexion: Finnland etwa, hier wie dort als Beispiel genannt, sollte nun an Schweden kommen. An dieser Stelle des Handschreibens ist mithin von einem Krieg die Rede, der durchaus »eine große Sache ${ }^{25}$ sein, doch dabei ein Kabinettskrieg bleiben, der nicht den Siegeszug des Nationalitätenprinzips einläuten, sondern die Ergebnisse früherer Kabinettskriege revidieren sollte. Und zwar einzig zu Lasten Rußlands.

In Paris wußte man, daß der 'großes Krieg, je nachdem ob er als Nationalitäten- oder als Kabinettskrieg konzipiert war, nur gegen oder mit Österreich geführt werden konnte, denn: "La grande guerre se fera en Pologne ${ }^{26}$." Wenn Napoleon nun ausgerechnet für Polen nicht zwischen >Unabhängigkeit « und >Übergabe - an einen Erzherzog? - unterschied, vielmehr durchgehend von $>$ Wiederherstellung s sprach, dann bedarf es schon interpretatorischen Überscharfsinns, um hier die Grenzen von 1772, dort jene von 1815 anzunehmen. Frühere Äußerungen ${ }^{27}$ belegen aber seine Überzeugung, sich durch staatsmännische Mäßigung der Kooperation Österreichs versichern zu können. Damit täuschte er sich wohl, soweit es speziell um Polen ging ${ }^{28}$, nicht jedoch grundsätzlich: Die Beteiligung an einem »remaniement purement politique ${ }^{29}$ war für die Monarchie kein Tabu, weder während des Krimkriegs noch in späteren Jahren. Sie konnte es auch kaum sein, wollte man nicht als Großmacht abdanken.

Dem britischen Verbündeten gegenüber verfuhr Napoleon insofern ehrlich, als er die Alternative eines nicht allein nach den Mitteln, sondern vor allem nach den Zielen 'großen، Kabinettskrieges nicht völlig unterschlug. Mit gezinkten Karten spielte er, als er zum offiziellen sSystem ‘ gerade jenes erkor, das, außer vielleicht bei Premierminister Henry Viscount Palmerston, in London keinerlei Sympathie genoß: den 'großen ( Nationalitäten- und Revolutionskrieg. Die Schlußfolgerung aus dieser Präsentation von >dreieinhalb`Systemen liegt auf der Hand: Der Kaiser wollte den Krieg nicht weiterführen, es sei denn zur Durchsetzung der österreichischen Friedensinitiative oder extensiv, in Form des Blockadekrieges. Erst im nachhinein hat er der "Unentschlossenheit ${ }^{30}$ Wiens an-

So nannte Napoleon den Nordfeldzug, Cowley an Clarendon, 4. 12. 1855, AGKK, III, 4 (wie Anm. 1), Nr. 236.

26 "[...] et la petite en Crimée«. Ein Wort Walewskis, Hübner an Buol, 2. 10. 1855, AGKK, I, 3 (wie Anm. 7), Nr. 18.

27 Vgl. Prinz Albert: >Memorandum on my Visit to Boulognes, [Anfang September 1854], Martin, Life (wie Anm. 17), S. 120.

28 Buol: "Wer solle Polen haben? Oestreich wolle es nicht, ebensowenig Preußen. Also eine neue Dynastie. Welche sie auch sei, nach einigen Jahren werde Polen ein Herd der Revolution sein und schließlich in Allianz mit Rußland treten. " Ernst II.: >Memorandum über den Aufenthalt in Wien<, [Juni 1854], StAC (wie Anm. 4), LA A 7169, f. 215.

29 Rechberg an Metternich, 20. 4. 1860, zit. nach Martin Senner, Die Donaufürstentümer als Tauschobjekt für die österreichischen Besitzungen in Italien (1853-1866), Stuttgart 1988, S. 281; vgl. Mensdorff an Apponyi, 26. 4. 1866, Il Problema Veneto e l'Europa 1859-1866. Raccolta di documenti diplomatici [...]. Ed. Istituto Veneto di Scienze, Lettere ed Arti. Vol. 1: Documenti diplomatici Austria. A cura di Richard Blaas, Venezia 1966, Nr. 502. 
gelastet, was in Wahrheit der Pariser Kriegsmüdigkeit und jener Interessendivergenz zuzuschreiben war, die seit dem Fall Sevastopol's das "Charakteristikum der Lage ${ }^{31}$ bildete: Frankreich konnte die seine für »recht günstig ${ }^{32}$ halten, und dies nicht zuletzt wegen Englands Schlappe am Redan, einer Scharte, die Volk und Regierung in der Kampagne von 1856 auszuwetzen hofften.

`Nationalere, französischere Ziele`

Schon im Oktober 1855 hatte Napoleon den britischen Verbündeten wissen lassen, Frankreich sei nur dann zu weiteren Kriegsanstrengungen bereit, wenn neue Ziele in Aussicht stünden, »des objets plus nationaux, plus Français « ${ }^{33}$ : Polen, Italien, das linke Rheinufer. Sie gleichzeitig anzustreben, hätte nichts weniger bedeutet, als die Konflikte von 1859, 1863 und $1870 \mathrm{zu}$ einem vorweggenommenen Weltkrieg zu bündeln, zu einem »europäischen 2 . December « ${ }^{34}$. Daß dergleichen gegen Englands Widerstand undurchführbar war, hatte der Bonaparte aus der von ihm intensiv studierten Geschichte des Ersten Kaiserreichs als bleibende Lehre gewonnen.

Von daher seine in Konfliktsituationen immer wieder zu beobachtende Nachgiebigkeit gegenüber London - sie zog ihm aus den Reihen seiner Minister sogar den Vorwurf zu, seinen Namen und Frankreichs Interessen zu vergessen -, sein ehrliches Bemühen um die Erhaltung der Entente cordiale ${ }^{35}$.

Von daher auch sein Wunsch nicht etwa nach einem Renversement des alliances, das ihn auf die gefährliche Bahn eines Ludwig XIV. und Napoleon I. geführt hätte, sondern nach Ergänzung der englischen "Vernunftheirat ${ }^{36}$ durch "eine enge und leidenschaftliche Liaison « mit einer kontinentalen Großmacht, wie er sie nach dem Pariser Kongreß russischen Diplomaten in verlockenden Farben ausmalte: "Ne pourrions-nous pas nous entendre à trois? Nous dominerons l'Europe ${ }^{37}$ ! Schon Ende 1855 war in einer vielbeachteten, von Napoleon

30 Denkschrift Napoleons, [Ende 1858], in: Emile Ollivier, L'Empire Libéral. Etudes, récits, souvenirs. Vol. 3: Napoléon III., Paris 1898, S. 538.

31 Walewski an Napoleon, 18. 1. 1856, Familienarchiv Walewski, C1, p. 68.

32 Monthérot an Walewski, 12. 9. 1855, AMAE (wie Anm. 10), CP Hesse-Cassel, 38, f. 58. — "Palmerston [...] est jaloux de nos succès en Crimée, jaloux du succès de Canrobert en Suède, jaloux de la tendance vers nous qui se manifeste en Allemagne, jaloux de notre position à Vienne, jaloux de notre rôle dans l'affaire de l'ultimatum autrichien, jaloux enfin de la position qui serait dévolue à la France si la paix se faisait." Walewski an Bourqueney, 9. 12. 1855, Familienarchiv Bourqueny, D 7/10.

33 Prinz Albert an Stockmar, 29. 10. 1855, Martin, Life (wie Anm. 17), S. 385.

34 ,Über die Lebensbedingungen und das Programm des zweiten französischen Kaiserthums`, 17. 11. 1854, in: Karl Friedrich Vitzthum von Eckstädt, St. Petersburg und London in den Jahren 1852-1864, Bd 1, Stuttgart 1886, S. 136.

35 » ve veux [...] que l'alliance anglaise survive à la paix.« Napoleon an Walewski, 18. 1. 1856, Acte şi Documente relative la istoria renascerei Romaniei. Ed. Ghenadie Petrescu şi Dimitrie A. Sturdza. Vol. 9, Bucureşci 1901, Nr. 2750; vgl. Cowley an Clarendon, 29. 1. 1856, AGKK, III, 4 (wie Anm. 1), Nr. 408; Hippolyte Fortoul, Journal. Vol. 2: 1. 7. 1855-4. 7. 1856. Publié par Geneviève Massa-Gille, Genève 1989, S. 205 (zum 19. 1. 1856). - Zur zeitgenössischen Verwendung des Begriffs vgl. Punch, or The London Charivari, vol. 27: 1. 7.-31. 12. 1854, S. 107.

36 Metternich an Rechberg, 26. 2. 1863, in: Hermann Oncken, Die Rheinpolitik Kaiser Na- 
inspirierten und eigenhändig redigierten Flugschrift die Krimkriegsallianz als "ewig ${ }^{38}$ bezeichnet, zugleich aber Rußland die Aussicht auf »neue und kostbare Bündnisse« eröffnet worden.

Von daher endlich seine Lieblingsidee, die Neuordnung des Kontinents nicht auf dem Schlachtfeld, sondern am grünen Tisch eines europäischen Kongresses $\mathrm{zu}$ verwirklichen, der "eine Lösung derjenigen Fragen brächte, die entweder beim Wiener Congreß schlecht erledigt worden, oder seitdem erst entstanden seien. [...] Polen, Italien u.s.w $\ll^{39}$.

An der Seite Englands konnten, so oder so, "große Dinge ${ }^{40}{ }^{0}$ vollbracht werden; ohne England blieb selbst jene der drei napoleonischen Visionen unerreichbar, die, bei entsprechenden Konzessionen und Kompensationen an Österreich ${ }^{41}$, in den Rahmen der Allianz vom 2. Dezember 1854 noch eben hineinpaßte: die Wiederherstellung Polens. Ein erster Schritt in diese Richtung wäre die Restauration Kongreßpolens gewesen ${ }^{42}$. Schon dieses Minimalprogramm war, im September 1855, dem britischen Kabinett zu weit gegangen, das ihm die Aufnahme in den Kanon der westlichen Kriegsziele versagt hatte.

Der Kaiser hat mithin, im Oktober und November 1855, mit einer Scheinalternative operiert: Er stellte der Beendigung des Krieges, soweit er »à grands sacrifices ${ }^{43}$ anstatt auf Sparflamme (d.h. als Blockadekrieg) zu führen war, das Szenario eines gesamteuropäischen Nationalitäten- und Revolutionskrieges gegenüber. Ein Szenario, aus dem die Orientalische Frage bis auf spärliche Spuren - Krim, Zirkassien - getilgt oder zur Gänze verschwunden war; ein Szenario, in dem auch die Russische Frage ${ }^{44}$ zum Alibi für 'französischere، Anliegen zu werden und, nach Napoleons Warnung an einen deutschen Staatsmann ${ }^{45}$, nicht

poleons III. von 1863 bis 1870 und der Ursprung des Krieges von 1870/71. Bd 1, Stuttgart 1926, Nr. 2.

37 Kiselev an Gorčakov, 6. 11. 1856, in: Recueil de Traités et conventions, conclus par la Russie [...], publié par Feodor de Martens. Vol. 15: Traités avec la France 1822-1906, St. Pétersbourg 1909 [Neudr. Nendeln 1969], S. 299; vgl. auch Brunnov an Gorčakov, 23. 5. 1856, ebd., S. 295 und Cowley an Clarendon, 23. 5. 1856, PRO (wie Anm. 5), FO 519/218.

38 Nécessité d'un Congrès pour pacifier l'Europe. Par un homme d'état, Paris 1855, S. 14, 4. - Vgl. Baumgart, Friede (wie Anm. 4), S. 44-46.

39 So faßte ein deutscher Gesprächspartner die Aussagen des Kaisers zusammen, Ernst II., Herzog von Sachsen-Coburg-Gotha, Aus meinem Leben und aus meiner Zeit. Bd 2, 6. Aufl., Berlin 1889, S. 281 (zum 25. 9. 1855).

40 Jérôme an J. Napoleon, 19. 9. 1854, AN (wie Anm. 3), 400 AP, 121, Nr. 168.

41 Vgl. J. Napoleon an Napoleon, April 1855, in: Ernest de Hauterive, Napoléon III et le Prince Napoléon. Correspondance inédite, 2. éd., Paris 1925, S. 88-90; Tagebucheintragung Gerlachs, 2. 12. 1854, Denkwürdigkeiten aus dem Leben Leopold von Gerlachs [...]. Nach seinen Aufzeichnungen hrsg. von seiner Tochter [Ulrike Agnes von Gerlach]. Bd 2, Berlin 1892, S. 251 f. - "Seit Prokesch vom Erzherzog Stephan zurück ist, affectirt er [...] Vorliebe für Mazurka, und wenn er zu mir kommt, fredonnirt er auf der Treppe einige falsche Töne, welche den letzten Tacten von sNoch ist Polen nicht verloren<, möglichst ähnlich sind.« Bismarck an Gerlach, 25. 10. 1854, in: Bismarcks Briefe an den General Leopold v. Gerlach. Hrsg. von Horst Kohl, Berlin 1896, Nr. 68.

42 Vgl. Walewski an Napoleon, 14. 9. 1855, Familienarchiv Walewski, C 1, p. 29; zum ganzen Baumgart, Friede (wie Anm. 4), S. 50 f. und AGKK, III, 4 (wie Anm. 1), S. 56.

43 Prinz Albert an Stockmar, 29. 10. 1855, Martin, Life (wie Anm. 17), S. 385.

44 Vgl. Hübner an Buol, 2. 10. 1855, AGKK, I, 3 (wie Anm. 7), Nr. 18; zum ganzen Baumgart, Friede (wie Anm. 4), S. 29-32 und AGKK, III, 4 (wie Anm. 1), S. 55-57.

45 Ludwig Frhr. von der Pfordten. - Vgl. Bismarck an Friedrich Wilhelm IV., 21. 12. 1855, in: Otto Fürst von Bismarck, Die gesammelten Werke. Bd 2: Politische Schriften 1. 1. 1855-1. 3. 1859. Bearb. von Herman von Petersdorff, Berlin [1924], Nr. 97. 
länger das europäische Recht, sondern der nationale Egoismus als Richtschnur zu dienen drohte. Mit anderen Worten: "La guerre du Rhin et des Alpes, la seule qui se puisse faire sans emprunt ${ }^{46}$. Dabei mußte seit der Ablehnung der relativ moderaten Polen-Initiative klar sein, daß England weder einen offenen Raubnoch einen Revolutionskrieg mittragen würde. Genausowenig konnte man die Augen davor verschließen, daß bei einem fliegenden Wechsel von der englischen zur russischen Allianz der Gewinn unsicher, der Preis jedoch hoch sein würde: Standen England und die deutschen Mächte auf dem Gegenkonto, dann war mit einem Mal Alexander II. Herr der Lage ${ }^{47}$ und mußte Frankreich, bevor es an Rhein und Po ernten konnte, den besten Früchten des Krimkriegs entsagen. Dazu war der Kaiser nicht bereit ${ }^{48}$. Wie hätte er auch der öffentlichen Meinung seines Landes gegenüber, so russophil sie sich neuerdings gebärden mochte ${ }^{49}$, die Politik der letzten drei Jahre quasi für non avenue erklären können ${ }^{50}$ ? Nein, Napoleon konnte die Konsequenzen eines Appells an die Nationalitäten im November 1855 kaum optimistischer beurteilen als im Februar: »Je me trouverais probablement seul contre toute l'Europe ${ }^{51}$.«

In den Tagen des Kriegsrats ging in Windsor ein weiteres Handschreiben aus den Tuilerien ein. Von verschiedenen 'Systemen des Krieges war nun keine Rede mehr, von seiner Fortsetzung nur in dem Sinne, daß sie schwerlich zu rechtfertigen sei, wenn nicht auch Österreich seinen Anteil an Geld- und Blutopfern übernehme. Denn: "D'après la convention" - dem österreichisch-französischen Memorandum vom 14. November 1855 - »l'Autriche est obligée de retirer son ambassadeur, et nous, nous poursuivons la guerre ${ }^{52} ! \ll$

\section{Vom `beschränkten`zum >großen`Krieg}

Würde sich Rußland weigern, die Friedensbedingungen ohne Wenn und Aber zu akzeptieren, so sah das 'Memorandum ' Konsultationen über Zwangsmaßnahmen gegen das Zarenreich vor. Diese sollten, nach den Vorstellungen von

46 Persigny an Walewski, 20. 11. 1855, AMAE (wie Anm. 10), CP Angleterre, 703, f. 34.

47 Als "l'arbitre de la situation « war Napoleon von Nesselrode apostrophiert worden, Denkwürdigkeiten (wie Anm. 41), S. 382 (zum 10. 1. 1856).

48 "Je veux bien la paix, mais je veux la rendre aussi chère que possible aux Russes, et non aussi bon marché que possible. "Napoleon an Walewski, 18. 1. 1856, Acte (wie Anm. 35), Nr. 2750.

49 Vgl. Denkschrift Prinz Alberts, 18. 2. 1856, AGKK, III, 4 (wie Anm. 1), Nr. 450.

50 Im Rückblick auf eine vergleichbare Situation, die von 1859, erklärte er: »Vis-à-vis des cadavres autrichiens et français de Solférino [...]. I'ancien état de choses ne pouvait revenir purement et simplement. Metternich an Rechberg, 9. 7. 1860, in: Henry Salomon, L'ambassade de Richard de Metternich à Paris, Paris 1931, S. 67.

51 ,Udienza di S.M. I'Imperatore, li 20 febbraio [1855] alle ore 2., in: Mario Degli Alberti, Per la storia dell'alleanza e della campagna di Crimea, 1853-1856. Lettere e documenti, Torino 1910, Nr. 69. - Eine Expansionspolitik großen Stils »devrait engendrer la coalition«, setzte Napoleon im Frühjahr 1857 auch Bismarck auseinander, Heinrich von Poschinger, Ein Achtundvierziger. Lothar Buchers Leben und Werke. Bd 3, Berlin 1894, S. 154 .

52 Napoleon an Victoria, 14. 1. 1856, Victoria, Letters (wie Anm. 18), S. 162. - Das >Memorandum c in: AGKK, I, 3 (wie Anm. 7), Nr. 33. 
Karl Ferdinand Graf von Buol-Schauenstein, Franz Josephs Außenminister, zunächst politischer Natur sein ${ }^{53}$, dann aber den Charakter eines beschränkten Krieges $^{54}$ annehmen: Truppenkonzentrationen entlang der gemeinsamen Grenzen, formelle Verpflichtung zur Verteidigung der türkischen Donaufront und Bekräftigung des österreichischen Mandats in den Fürstentümern, schließlich die militärische Besetzung Bessarabiens, von der man hoffte, sie werde ähnlich unblutig verlaufen wie seinerzeit jene von Moldau und Walachei, die "Drangsale des offenen Krieges vermeiden ${ }^{55}$. Wesentlicher Bestandteil dieses Pressionssystems war fürs erste die Ankündigung, danach die Verhängung einer Seeblockade, um Preußens wohlwollender Neutralität für Rußland und seinem Waffenhandel mit dieser Macht ein Ende zu setzen. Sobald Berlin indes dem österreichischen Ultimatum beitrat, war es an den Beratungen über das weitere Vorgehen zu beteiligen ${ }^{56}$.

Aus seinen Bedenken gegen einen 'großen Krieg hat Buol nie einen Hehl gemacht: Selbst im günstigsten Fall, wenn es der Kontrolle der Kabinette nicht entglitt, mochte ein solches Unternehmen mehr Probleme aufwerfen als lösen. Doch hat er sich gehütet, Österreichs Kriegseintritt kategorisch auszuschließen ${ }^{57}$, lediglich betont, daßs dieser dem diplomatischen Bruch mit Petersburg nicht auf dem Fuß folgen werde ${ }^{58}$. Zuvor müsse zwischen Wien und seinen Verbündeten Einvernehmen darüber hergestellt werden, welche Kriegsziele man erreichen wolle, welche Mittel hierfür einzusetzen seien ${ }^{59}$ und wie die Rollenverteilung auf dem Kriegstheater aussehen solle. - Sie, meinte der Minister, werde sich aus der vorgeschalteten Phase diplomatischen und militärischen Drucks heraus entwickeln ${ }^{60}$. Darüber, wie dieses Pressionssystem (»la guerre sans la bataille ${ }^{61}$ ) im

53 „La Russie [...] mise au ban de l'Europe, [...] c'est la chance presque certaine de son retour à la raison." Bourqueney an Walewski, 14. 11. 1855, AMAE (wie Anm. 10), CP Autriche, 461, f. 117.

54 >Guerre restreinte ‘ bzw. >système de pression`im Unterschied zu >grande guerre<, vgl. Serre an Walewski, 28. 10. 1855, ebd., f. 57-64.

55 Buol an Franz Joseph, 9. 11. 1855, AGKK, I, 3 (wie Anm. 7), Nr. 32.

56 Vgl. Serre an Walewski, 28. 10. 1855, AMAE (wie Anm. 10), CP Autriche, 461, f. 62 f.; österreichisch-französisches Memorandum, 14. 11. 1855, AGKK, I, 3 (wie Anm. 7), Nr. 33.

57 Seine Äußerung vom September 1855 (vgl. Baumgart, Friede - wie Anm. 4 - S. 77, Anm. 201) kann nicht in diesem Sinne interpretiert werden, weil sie unter dem Vorbehalt steht, daß eine bloße >Demonstration ' Österreichs und Deutschlands hingereicht hätte, Rußland zum Einlenken zu bewegen. Buol kalkulierte die Ultima ratio ein, forderte allerdings, der Krieg müsse den ‘besonderen Interessen Österreichs` sowie >Europas Interessen im allgemeinen bündeten`, vgl. Buol an Colloredo, 16. 4. 1855, AGKK, Serie I, Bd 2: 30. 3. 1854 bis 9. 9. 1855. Bearb. von Werner Zürrer. München, Wien 1980, Nr. 434; Buol an Hübner, 17. 11. 1855, AGKK, I, 3 (wie Anm. 7), Nr. 40.

58 Vgl. Buol an Hübner, 29. 12. 1855, AGKK, I, 3 (wie Anm. 7), Nr. 92; Bourqueney an Walewski, 14. 11. 1855, AMAE (wie Anm. 10), CP Autriche, 461, f. 115 f.

59 Vgl. Serre an Walewski, 28. 10. 1855, AMAE (wie Anm. 10), f. 57-64.

60 »L'entente à intervenir [...] implique forcément la combinaison des rôles de chacune des trois Puissances dans l'action commune contre la Russie, ainsi que la corrélation préétablie des opérations militaires respectives. [...] Tous les rôles seraient définis dans le présent, toutes les conduites reliées pour l'avenir.« Bourqueney an Walewski, 14. 11. 1855, ebd., f. 116 f.

61 Ein Wort Buols, Clarendon an Cowley, 16. 11. 1855, AGKK, III, 4 (wie Anm. 1), Nr. 161; vgl. Buol an Hübner, 17. 11. 1855, AGKK, I, 3 (wie Anm. 7), Nr. 40. Böse Zungen spra- 
einzelnen zu gestalten wäre, sollten sich die Dezemberverbündeten deshalb unverzüglich nach Abweisung des Ultimatums verständigen.

Buol wünschte zu diesem Zweck, und der Wortlaut des 'Memorandums ' gab ihm recht, den Zusammentritt einer Konferen $z^{62}$. Er wollte sie aber keineswegs als Kriegsrat verstanden wissen. So bezeichnete er ihr Thema, statt mit den Worten "Action gegen Rußland ${ }^{63}$, mit "Art und Ausdehnung der gegen Rußland anzuwendenden Mittel«, während er im Hinblick auf die Lage nach dem 18. Januar das eindeutige »Krieg « durch »Complication« ersetzte. Auch sein britischer Kollege, George William Earl of Clarendon, hielt diese Konferenz nicht für einen Kriegsrat, sondern, da die bestehenden Kommunikationsmöglichkeiten völlig ausreichend seien, schlicht für entbehrlich ${ }^{64}$. Dies konnte freilich nur für den Fall gelten, daß der 'große $<$ Kriegsrat in Permanenz ${ }^{65}$ tagte, mithin die Teilnahme Österreichs jederzeit möglich war, und sei es im Wege schriftlicher Konsultation $^{66}$.

Nach dem Scheitern der letzten österreichischen Friedensinitiative, der Wiener Konferenzen vom Frühjahr 1855, hatten sich die Westmächte in ihrer Erwartung getäuscht gesehen, der Kaiserstaat werde nun seinen militärischen Verpflichtungen aus dem Allianztraktat nachkommen. Schlimmer noch, sie hatten befürchten müssen, ihr platonischer Bundesgenosse werde den Rückzug in die Reihen der Neutralen oder gar der Heiligen Allianz antreten ${ }^{67}$. Insbesondere Frankreich, wo Kriegsmüdigkeit grassierte ${ }^{68}$, mußte daran gelegen sein, die Monarchie so früh und so fest wie möglich in die militärischen Planungen einzubinden. Andernfalls setzte man sich in der Tat dem von Napoleon angedeuteten $^{69}$ Vorwurf aus, ihr die Kastanien aus dem Feuer $\mathrm{zu}$ holen. Buol wiederum hatte im Oktober 1855 deutlich erklärt, angesichts der finanziellen Lage des Reiches seien erneute Rüstungs- und Mobilmachungsmaßnahmen nur vertretbar "en vue d'une guerre déjà résolue " ". Seine Vermutung, es werde mindestens den ganzen Winter in Anspruch nehmen, bis Österreich kriegsbereit sei, legt den Schluß nahe, daß er mit einem solchen Entscheidungsprozeß, einem Kriegsrat eben, spätestens für Dezember gerechnet hat.

chen von "hostilité pacifique», Gramont an Thouvenel, 15. 12. 1855, AN (wie Anm. 3), 192 MI, 6, Nr. 10.

62 "[...] les Puissances alliées se réuniraient sans retard.« Österreichisch-französisches Memorandum, 14. 11. 1855, AGKK, I, 3 (wie Anm. 7), Nr. 33; vgl. Aide-Mémoire Buols, 11. 1. 1856, ebd., Nr. 112.

63 Buol an G. Esterházy, 14. 1. 1856, ebd., Nr. 127.

64 Vgl. Clarendon an Seymour, 8. 1. 1856, AGKK, III, 4 (wie Anm. 1), Nr. 318.

65 Gramont an Thouvenel, 15. 12. 1855, AN (wie Anm. 3), 192 MI, 6, Nr. 10.

66 Vgl. Clarendon an Seymour, 8. 1. 1856, AGKK, III, 4 (wie Anm. 1), Nr. 319.

67 Vgl. etwa Walewski an Clarendon, 31. 5. [1855], BLO (wie Anm. 10), Clarendon Dep., c. $33, \mathrm{f} .431 \mathrm{f}$.

68 "[...] not [...] more disposed to sanction a loan, or to furnish conscripts for the frontier of the Rhine, than for the conquest of Circassia and Georgia «. Cowley an Clarendon, 24. 10. 1855, AGKK, III, 4 (wie Anm. 1), Nr. 119.

69 Vgl. Cowley an Clarendon, 12. 1. 1856, ebd., Nr. 335.

70 Serre an Walewski, 28. 10. 1855, AMAE (wie Anm. 10), CP Autriche, 461, f. 61. In österreichischen Militärkreisen wurden für die Aufrüstung 500 Millionen Francs - umgerechnet 200 Millionen Gulden - veranschlagt, d.h. fast $30 \%$ mehr, als der gesamte Verteidigungsetat für 1856 überhaupt ausmachte, vgl. Forth-Rouen an Walewski, 24. 12. 1855, AMAE (wie Anm. 10), CP Saxe, 117, f. 337 f.; Grünne an Franz Joseph, 21. 11. 1855, AGKK, I, 3 (wie Anm. 7), Nr. 42. 


\section{»Keine politischen Diskussionen!«}

Die Ankündigung eines 'großen< Kriegsrats ließ mit einiger Selbstverständlichkeit erwarten, dort werde der >große< Krieg auf der Tagesordnung stehen. »The outline is clear ${ }^{71}$, hatte Palmerston festgestellt: Englische und türkische Truppen sollten von Kleinasien aus gegen Georgien und Zirkassien operieren, französische und schwedische in Finnland und gegen Petersburg. Im Schwarzen Meer würde London, in der Ostsee Paris das Oberkommando übernehmen, die Einheit der Allianz durch symbolische Kontingente auf beiden Schauplätzen demonstriert werden.

Dieser Plan war ohne österreichische Beteiligung durchführbar, erforderte folglich keine Konsultation Wiens. Daß man in London einer fortdauernden militärischen Passivität des Kaiserstaates ziemlich gelassen entgegensah, führte der wohlinformierte Herzog von Gramont auf diesen Umstand zurück ${ }^{72}$.

Napoleon hätte es als dem designierten Präsidenten des Kriegsrats oblegen, Österreich an den Konferenztisch zu bitten ${ }^{73}$. Zumindest eine Einladung an Franz Josephs Gesandten in Paris, analog zur Beteiligung des britischen Botschafters, Henry Earl of Cowley, wäre auch kurzfristig noch möglich gewesen, in dem Moment nämlich, als der Kaiser aus heiterem Himmel die große baltische Kampagne für undurchführbar erklärte, weil die hierfür benötigten Kräfte nicht rechtzeitig aus dem Orient in die Ostsee verlegt werden könnten ${ }^{74}$. Da an der Seine ein Abzug von der Krim schon seit gut zwei Monaten ventiliert worden war, kann dies für Napoleon kaum eine neue Erkenntnis gewesen sein.

Weit eher ein vorgeschobenes Argument. Sein wahrer Beweggrund war wohl derselbe, den er, eine Woche später, in dem Handschreiben an Victoria anklingen ließ: Frankreich wollte nicht länger Gut und Blut für fremde Interessen opfern, mochten sie auch identisch mit jenen Europas sein - für das österreichischer Bessarabien sowenig wie für das sschwedische< Finnland. Die interessierten Mächte sollten selbst in die Schranken treten. Paris war, was Schweden anging, höchstens bereit, den Schritt über den Rubikon durch ein bescheidenes Expeditionskorps von $20--25000 \mathrm{Mann}^{75}$ zu unterstützen.

Hat Napoleon überhaupt jemals ernstlich an eine großangelegte Ostsee-Operation gedacht, sie nicht vielmehr nur als Beruhigungsmittel für den britischen Partner benutzt? Während der sich in dem Glauben wiegte, in den Tuilerien sei man für einen neuen Nordischen Krieg fast so begeistert wie für den Frieden, war das Projekt dort bereits auf ein reines Marineunternehmen geschrumpft. Der

71 Palmerston an Clarendon, 8. 11. 1855, AGKK, III, 4 (wie Anm. 1), Nr. 147.

72 Vgl. Gramont an Thouvenel, 15. 12. 1855, AN (wie Anm. 3), 192 MI, 6, Nr. 10.

73 Vgl. Clarendon an Cowley, 3. 12. 1855, AGKK, III, 4 (wie Anm. 1), Nr. 233.

74 Vgl. Cowley an Clarendon, 9. 1. 1856, ebd., Nr. 323. - Während des Kriegsrats wurden dann für den Abzug der französischen Orient-Armee von 154000 Mann süber 6 Monater angesetzt (Gutachten Gravières, 14. 1. 1856, PRO - wie Anm. 5 - WO 33/2 B, S. 11, vgl. auch S. 12). Die mehrfach genannte Zahl von 100000 Mann (so etwa Cowley an Clarendon, 30. 11. 1855, AGKK, III, 4 - wie Anm. 1 - Nr. 225) hätte demnach im Frühsommer im Baltikum verfügbar sein können, der für Operationen in diesen Breiten ohnehin als die beste Jahreszeit galt.

75 Vgl. Cowley an Clarendon, 9. 1. 1856; dagegen Clarendon an Stratford, 28. 12. 1855, AGKK, III, 4 (wie Anm. 1), Nr. 323, 295. 
österreichische Gesandte, Joseph Alexander Frhr. von Hübner, erfuhr aus dem Munde des Kaisers, mittels ihrer Schwimmenden Batterien und weittragenden Mörser neuartiger Bauart würden die Anglo-Franzosen Rußlands Ostseefestungen zerstören - Sveaborg, Reval und Kronstadt ${ }^{76}$. Dem Mittelsmann nach St. Petersburg gegenüber, Albin Leo Graf von Seebach, war nur von der Zerstörung des bedeutendsten der drei Ziele sowie von der Fortsetzung der Blockade im Schwarzen Meer die Rede ${ }^{77}$, obwohl es doch im Interesse der Westmächte lag, die heraufziehende Gefahr so schwarz wie möglich zu schildern ${ }^{78}$. - Als der französische Imperator in der dritten Sitzung des Kriegsrats auch Truppenlandungen und die Errichtung von Stützpunkten für künftige größere Operationen zur Diskussion stellte und trotz allgemeinen Widerspruchs auf der Durchführbarkeit eines Winterkrieges im Baltikum bestand, da muß ihn das Bedürfnis nach einer echten militärischen Alternative - "expédition contre $S^{\mathrm{k}}$ Pétersbourg “ ${ }^{79}$ - übermannt haben. Angesichts der Unwägbarkeiten der politischen Situation ein nur zu begreiflicher Wunsch ${ }^{80}$. Es war allerdings bloß ein Strohfeuer: Der Entschluß, am 15. Januar nicht etwa eine außerordentliche Sitzung des Kriegsrats anzuberaumen, sondern in vorverlegter Ministerratssitzung ${ }^{81}$ die russischen Gegenvorschläge zu erörtern, signalisierte unübersehbar, daß man eine politische Lösung wünschte.

Wenn die Ostsee als Bühne für einen 'großen Krieg ausschied, dann blieben dafür noch Polen und Deutschland; immer vorausgesetzt, Napoleon wäre zu einem solchen Unternehmen bereit gewesen, hätte er es nur >à la Française ${ }^{82}$ aufziehen dürfen. Der dritte Tagesordnungspunkt, den der Kaiser für die Eröffnungssitzung des Kriegsrats vorbereitet hatte, handelte in der Tat von diesen beiden Schauplätzen: "Qu'y a-t-il à faire en Allemagne avec l'Autriche? Y auraitil avantage à envoyer de Crimée par le Danube et les principautés $60000 \mathrm{~h}[\mathrm{om}$ mes] en Galicie au lieu à les envoyer de France et par où passeraient-ils ${ }^{83}$ ? « Doch kamen diese Fragen lediglich zur Sprache, um zur Chefsache erklärt und vertagt

76 Vgl. Hübner an Buol, 17. 12. 1855, AGKK, I, 3 (wie Anm. 7), Nr. 74.

77 Daß er gegen Kronstadt ausschließlich von See her operieren wollte, darauf läßt Napoleons Betonung »des perfectionnements apportés dans la science navale" schließen, Etude diplomatique sur la Guerre de Crimée. Par un ancien diplomate [Alexandre de Jomini]. Vol. 2, St. Pétersbourg 1878, S. 381.

78 "It might be useful that. Count Esterhazy should spargere voces to this effect when he gets to S'Petersburg. "Clarendon an Seymour, 18. 12. 1855, AGKK, III, 4 (wie Anm. 1), Nr. 276.

79 »[...] hivernage de 100000 hommes à Sweaborg etc.«, Aufzeichnung J. Napoleons, 14. 1. 1856, AN (wie Anm. 3), 400 AP, 119, Nr. 6; vgl. Aufzeichnung Cambridges, 14. 1. 1856, AGKK, III, 4 (wie Anm. 1), Nr. 341.

80 "It is characteristic of the Emperor that he likes to have two strings to his bow.« Hübner an Buol, 11. 6. 1856, in: Conversations with Napoleon III. A Collection of Documents, mostly unpublished and almost entirely diplomatic, selected [...] by Victor Wellesley and Robert Sencourt, London 1934, S. 114.

81 Vgl. Aufzeichnung Baroches, 15. 1. 1856, Bibliothèque Thiers (BT), Fonds Baroche, 1015, f. 92-94.

82 „Das Land ist den Krieg müde, qui se fait à l'Anglaise, wobei man nicht plündern kann, sondern für Alles bezahlen muß und zuletzt keine Eroberung bekommt. « Denkschrift Prinz Alberts, 18. 2. 1856, AGKK, III, 4 (wie Anm. 1), Nr. 450.

83 Aufzeichnung Napoleons, [10. 1. 1856], AN (wie Anm. 3), 400 AP, 55, Nr. 37 bis. 
$z u$ werden, bis Wiens Kriegseintritt eine vollendete Tatsache ${ }^{84}$ sein würde. Daß gerade der durch Buol von einem vorgängigen gemeinsamen Kriegsrat abhängig gemacht worden war - also umgekehrt ein Schuh daraus wurde -, ist offenbar keinem der Teilnehmer aufgefallen. Hingegen entging ihnen nicht, daß eine rernsthafte ${ }^{85}$ und vertiefter Prüfung bestimmter Optionen, beispielsweise eines Feldzugs in Bessarabien, schwer möglich war, solange Österreichs Rolle ausgeblendet blieb. Als sie »beiläufig “ ${ }^{86}$ angesprochen wurde, reagierte der kaiserliche Sitzungspräsident mit dem Hinweis, politische Erörterungen seien den Regierungen vorbehalten. Die Mahnung von Pélissiers Vorgänger, François-Certain Canrobert, sich vor den Details erst einmal dem Gesamtbild zuzuwenden, fand kein Gehör.

\section{Aufmarschbasis Bessarabien?}

Im russischen Bessarabien, »durch eine Offensive jenseits der Gränze, eine Demonstration zu machen ${ }^{87}$ — das hielt nicht allein der Generaladjutant Kaiser Franz Josephs für ein Zwangsmittel noch gerade unterhalb der Schwelle zum 'großen K Krieg, sondern, wie erwähnt, auch Buol. Da dieser ausdrücklich betont hatte, es sei nicht beabsichtigt, Österreichs Verbündete hinsichtlich ihres künftigen Operationsgebiets irgendwie $z u$ beschränken ${ }^{88}$, war die Beteiligung englischer, französischer oder türkischer Truppen an einer solchen Demonstration sehr wohl denkbar, falls die nach dem 18. Januar zu treffende Vereinbarung ${ }^{89}$ zwischen den Alliierten das vorsah. Andererseits brauchte Wien gar nicht involviert zu werden, wenn die Seemächte eine Wiederholung des unseligen Dobrudža-Unternehmens von 1854 in Kauf nahmen, indem sie anstelle der österreichischen Donaufront die türkische zum Ausgangspunkt ihrer Offensive wählten.

Im Kriegsrat ist die Bessarabien-Operation im Rahmen des ersten, der Krim gewidmeten Fragenkomplexes ${ }^{90}$ zur Sprache gekommen. Dabei sollte es ausschließlich darum gehen, den Raum zwischen Pruth und Dnestr zu besetzen und

"[...] in the event of an active participation on the part of Austriak. Aufzeichnung Cambridges, 10. 1. 1856, AGKK, III, 4 (wie Anm. 1), Nr. 328.

85 Aufzeichnung J. Napoleons, 12. 1. 1856, AN (wie Anm. 3), 400 AP, 119, Nr. 6; Gutachten Gravières, 14. 1. 1856, PRO (wie Anm. 5), WO 33/2 B, S. 16.

86 Aufzeichnung J. Napoleons, 10. 1. 1856, AN (wie Anm. 3), 400 AP, 119, Nr. 6. - Wahrscheinlich war dies die "short desultory conversation", auf die Napoleons Verdikt "no political discussions" folgte, Aufzeichnung Cambridges, 10. 1. 1856, AGKK, III, 4 (wie Anm. 1), Nr. 328.

87 Ministerkonferenz, 27. 11. 1855, AGKK, I, 3 (wie Anm. 7), Nr. 49.

88 Vgl. Bourqueney an Walewski, 14. 11. 1855, AMAE (wie Anm. 10), CP Autriche, 461, f. $116 \mathrm{f}$.

89 Das österreichisch-französische Memorandum verwendet den Terminus "concerter« (AGKK, I, 3 - wie Anm. 7 - Nr. 33), was Buol als "la conclusion d'un accord " interpretierte, d.h. als Zeichnung eines völkerrechtlichen Aktes, etwa einer Konvention, Bourqueney an Walewski, 14. 11. 1855, AMAE (wie Anm. 10), CP Autriche, 461, f. 115.

90 Vgl. Aufzeichnung Cambridges, 10. 1. 1856 (Anlage 1), AGKK, III, 4 (wie Anm. 1), Nr. 328 
zu halten. Napoleon sprach nachträglich von einer reinen Diversion, deren Ziel es gewesen wäre, Rußland zur Verringerung oder zum Abzug seiner Krimtruppen zu nötigen, und verwarf das Unternehmen als weniger erfolgversprechend, sicherlich aber langwieriger als eine Diversion auf der Halbinsel selbst, wie er sie schon im September 1855 vorgeschlagen hatte ${ }^{91}$. Von seinen Dimensionen her $^{92}$ blieb es allerdings nur unwesentlich hinter der sgroßen ‘ baltischen Expedition (mit 120000 Mann) zurück und stellte die Operationen in Polen und Finnland (mit jeweils 60000 Mann), deren Umfang immerhin dem der Krim-Armada vom September 1854 entsprochen hätte, deutlich in den Schatten.

Napoleons dritter, vorerst gestrichener Tagesordnungspunkt erfuhr im Protokoll seines Vetters folgende Wiedergabe: Es handele sich darum, das Zarenreich "sur ses frontières du centre ${ }^{93}$ anzugreifen, nämlich »en Bessarabie ou sur le haut Danube avec l'Autriche«. Der Kaiser dürfte demnach diesen Fragenkomplex mündlich anders formuliert haben als schriftlich; jedenfalls muß aus seinen Ausführungen zweierlei hervorgegangen sein:

Zum einen die Präzisierung der künftigen austro-französischen Kooperation sin Deutschland d durch deren Lokalisierung »am Oberlauf der Donau«, also in Süddeutschland. - Militärisches Ziel wäre der Aufbau einer >Operationslinie ${ }^{94}$ zur Unterstützung eines österreichischen Aufmarschs gegen Rußland sowie die Bedrohung von Preußens Flanke gewesen, politisches Ziel die Beendigung von Deutschlands Neutralität ${ }^{95}$. In der französischen Generalität war man überzeugt, die Konzentration von 150000 Mann an der Ostgrenze, sogar die bloße Ankündigung einer 'Rheinarmee werde den Bund auf die Seite der Westmächte bringen und ihn veranlassen, in Petersburg auf die Annahme des Ultimatums zu dringen: "L'Allemagne ne couvre la Russie que parcequ'elle ne croit pas que nous nous déciderons à la traverser. La paix est peut-être immédiatement au bout de cette menace ${ }^{96}$." Die zweite Stufe des Pressionssystems wäre dann die Präsenz französischer Truppen auf deutschem Boden gewesen. Sahen selbst die früheren Rheinbundstaaten ihr mit gemischten Gefühlen entgegen, so hatte Berlin den Westmächten darüber Brief und Siegel gegeben, indem es als Vorbedingung eines Bündnisses den Verzicht auf diese Option verlangte ${ }^{97}$. In der dritten

91 Vgl. Denkschrift Napoleons, 20. 1. 1856, PRO (wie Anm. 5), WO 33/2 B, S. 55; Napoleon an Walewski, 14. 9. 1855, Rousset, Histoire (wie Anm. 1), S. 404-407.

92100000 Mann. Für den Transport dieser Armee - 20000 Pferde und 198 Geschütze inklusive - wären 304 Handels- und 140 Kriegsschiffe erforderlich gewesen. Vgl. Aufzeichnung Napoleons, [10. 1. 1856], AGKK, III, 4 (wie Anm. 1), Nr. 328 (Anlage 1); Gutachten Gravières, 14. 1. 1856, PRO (wie Anm. 5), WO 33/2 B, S. 13, 18. - Zu den übrigen Zahlenangaben vgl. Gutachten 'Comment peut-on prendre St. Pétersbourg?‘, [19. 1. 1856?], PRO (wie Anm. 5), WO 33/2 B, S. 48-50, und Aufzeichnung Napoleons, [10. 1. 1856], AN (wie Anm. 3), $400 \mathrm{AP}, 55, \mathrm{Nr} .37$ bis.

93 Aufzeichnung J. Napoleons, 10. 1. 1856, AN (wie Anm. 3), 400 AP, 119, Nr. 6.

94 Gutachten Bosquets, 16. 1. 1856, PRO (wie Anm. 5), WO 33/2 B, S. 34; vgl. Thouvenel an Bourqueney, 22. 7. 1854, Familienarchiv Bourqueney, D 4/1.

95 Napoleon hatte schon früher durchblicken lassen, für Frankreich könnten »des arrangemens expectans" keine Dauerlösung sein, »qui dans certaines éventualités, pourraient la replacer en présence des années 1814 et 15 «, Chimay an Ernst II., 13. 6. 1855, StAC (wie Anm. 4), LA A 7174, f. [178 a].

96 Gutachten Bosquets, 16. 1. 1856, PRO (wie Anm. 5), WO 33/2 B, S. 34; vgl. die Gutachten Canroberts und Niels, 16. und 17. 1. 1856, ebd., S. 32 f., 41 f.; Espinasse an Napoleon, 6. 12. 1855, AN (wie Anm. 3), $400 \mathrm{AP}, 55$, Nr. 4.

97. Vgl. Méneval an Thouvenel, 12. 3. 1855, AMAE (wie Anm. 10), PA Thouvenel, 13, 
Stufe, bereits jenseits der Schwelle zum sgroßen ‘ Krieg, wäre schließlich Rußlands $>$ deutsche Provinz ${ }^{98}$, Preußen, zum Ziel militärischer Aktionen geworden, hätte eine Vision vom Vorjahr Wirklichkeit werden können: »Berlin pourrait bien être substitué à Sébastopol ${ }^{99}$."

Zum anderen, hinsichtlich der möglicherweise über den Unter- statt über den Oberlauf der Donau snach Galizien ‘ zu verlegenden Streitkräfte: Sollte, da die erstgenannte Route nun einmal die kürzere war und Bessarabien gewissermaßen am Wege lag, eben nicht Galizien, sondern Bessarabien als Aufmarschbasis dienen? Diese Annahme würde den für eine Diversion recht großzügigen Ansatz von $100000 \mathrm{Mann}^{100}$ - Österreicher wie stets nicht eingerechnet - erklären, hätten doch hinter Bessarabien mit seinen 41000 Verteidigern ${ }^{101}$ als eigentliches Ziel die alten polnischen Provinzen Podolien und Wolhynien gestanden.

Allein Polen, die Achillesferse des russischen Bären, erlaubte es, ihn in einem 'großen Krieg zu stellen. Einen solchen in Übersee zu führen - dazu zählte, solange Mitteleuropa neutral blieb, auch das Baltikum - , hielten Frankreichs Heerführer für unökonomisch und politisch bedenklich ${ }^{102}$. Ihre volle Wirkung konnte die erhoffte militärische Beteiligung Österreichs und Deutschlands, wie Prinz Napoleon meinte, erst zwischen Warthe und Bug entfalten. Diese Auffassung dürfte der Kaiser geteilt haben, der oft genug erklärt hatte, er werde den Krieg allenfalls für die Restauration Polens fortsetzen ${ }^{103}$. Schon im Februar 1855, als eine Militärkonvention mit Wien zur Verhandlung stand, hatte er einen diesbezüglichen Schlachtplan entwickelt, ohne freilich seine politischen Hintergedanken preiszugeben: Rußland sollte von Galizien, der Moldau und der Bukowina aus angegriffen, zugleich durch eine Demonstration in der Ostsee abgelenkt und auf diese Weise, selbst ohne Preußens Beitritt zur Koalition, zum Rückzug hinter die Weichsel genötigt werden. Sich mit der Besetzung einer

f. 171 f.; Méneval an Walewski, 11. 1. 1856, AMAE (wie Anm. 10), PA Walewski, 20, f. 114; Friedrich Wilhelm IV. an Arnim, 27. 2. 1855, Borries, Preußen (wie Anm. 14), Anlage 26.

98 Vgl. Clarendon an Bloomfield, 1. 1. 1856; Cowley an Clarendon, 4. 12. 1855, AGKK, III, 4 (wie Anm. 1), Nr. 303, 236.

99 Chimay an Ernst II., 21. 2. 1855, StAC (wie Anm. 4), LA A 7174, f. 153.

100 Die Hälfte wurde als ausreichend angesehen, vgl. Gutachten La Marmoras, 17. 1. 1856, PRO (wie Anm. 5), WO 33/2 B, S. 35. Das zeigt auch Wiens Forderung von 150000 Mann alliierter Truppen für einen Feldzug »in Pohlen «, die Clarendon, wie alle österreichischen Zahlen, für weit überhöht hielt, Hess-Memorandum, 1. 3. 1855, AGKK, I, 2 (wie Anm. 57), Nr. 381; vgl. Walewski an Drouyn de Lhuys, 17. 3. 1855, AMAE (wie Anm. 10), PA Walewski, III bis, 17.

101 Vgl. Denkschrift Napoleons, 14. 2. 1855, SHAT (wie Anm. 5), G 1, 14. Aufgrund des ständigen Abflusses an die Krimfront dürfte die Truppenstärke Anfang 1856 eher niedriger gewesen sein.

102 »Le Gouvernement est hors d'état de la diriger, en raison du temps nécessaire pour échanger des communications. De là, nécessité de confier au commandant des pouvoirs extraordinaires, qui sont toujours un danger.« J. Napoleon an Napoleon, Âpril 1855, Hauterive, Napoléon III. (wie Anm. 41), S. 87. Vgl. auch die Gutachten J. Napoleons und Niels, 17. 1. 1856, AN (wie Anm. 3), 400 AP, 55, Nr. 2; PRO (wie Anm. 5), WO $33 / 2$ B, S. 40.

103 Vgl. Cowley an Clarendon, 24. 9. 1855, Conversations (wie Anm. 80), S. 92 f.; Granville an Clarendon, 7. 10. 1855, verfilmt in Oriental Question (wie Anm. 5), XVII, RA (M), G 39/52; Tagebucheintragung Grevilles, 6. 12. 1855, in: The Greville Memoirs 1814-1860. Ed. by Lytton Strachey and Roger Fulford. Vol. 7: 1854-1860, London 1938, S. 173. 
Grenzprovinz zu begnügen, bringe gar nichts: "Entrer en Bessarabie, occuper une portion de ce pays ne décidera pas [...] la Russie à faire la paix ${ }^{104}$.«

Militärisch allzu aufwendig für eine bloße Diversion, wäre das BessarabienUnternehmen auch im Frühjahr 1856 politisch nur sinnvoll gewesen als Vorspiel zum 'großen Krieg in Polen, oder aber dann, wenn man dieser Eroberung einen ähnlich hohen Eigenwert beigemessen hätte wie der Befreiung Zirkassiens und Georgiens. Auf englischer Seite ist Bessarabien durchaus als nützliches Glied in dem um Rußland zu schmiedenden Gürtel kleinerer und größerer Pufferstaaten betrachtet worden ${ }^{105}$. Nicht so von Napoleon, dem die Briten keineswegs zu Unrecht Leichtfertigkeit und Desinteresse attestierten ${ }^{106}$, wo es um die Feinheiten der Orientalischen Frage ging. Statt für die >bessarabischen Heidegebieter eine weitere Runde auf dem Schlachtfeld zu riskieren, zeigte er sich höchst eifrig, Rußland mit ihrer Hilfe eine goldene Brücke zum Frieden zu bauen.

\section{Kompensationsobjekt Bessarabien}

Weit mehr als das Damoklesschwert des Fünften Punktes, das immerhin ein zweischneidiges war ${ }^{107}$, blockierte die Bessarabien-Frage den Weg zum Frieden. Alexander II. könne, hieß es, mit der Abtretung von 400000 Seelen seinen Thron in Gefahr bringen; bevor Rußland mit einem Federstrich auf die strategisch so wertvolle Flußgrenze an Donau und Pruth verzichte, werde es eher den alliierten Armeen Petersburg preisgeben und einen Krieg im Stil von 1812 wagen ${ }^{108}$.

An Bessarabien war die feingesponnene Domino-Theorie des Quai d'Orsay zuschanden geworden, wonach die deutschen Staaten durch ihren Anschluß an den österreichischen Friedensschritt zunächst Preußen isolieren sollten, dieses daraufhin in Petersburg notgedrungen zum Anwalt der westlichen Forderungen werden und Rußland schließlich kein Ausweg mehr bleiben würde, als vor dem Ultimatum zu kapitulieren. Statt seine Rolle in diesem noch rein diplomatischen Pressionssystem zu spielen, hatte das Dritte Deutschland die bessarabische ,Grenzrektifikation`zum willkommenen Vorwand genommen, sich den Konsequenzen seines politischen Flirts mit Paris - symbolisiert durch die Doppelvisite der Außenminister Sachsens und Bayerns im Herbst 1855 - zu entziehen ${ }^{109}$.

104 Hübner an Buol, 10. 2. 1855, AGKK, I, 2 (wie Anm. 57), Nr. 364.

$105 \mathrm{Vgl}$. Argyll an Clarendon, 4. 1. 1856, AGKK, III, 4 (wie Anm. 1), Nr. 306.

106 Vgl. Clarendon an Stratford, 14. 12. 1855, PRO (wie Anm. 5), FO 78/1069.

107 "Der $5^{\text {te }}$ Punkt legt keine Verbindlichkeit auf, er hat eine gleiche Geltung für alle kriegführenden Theile.« Buol an Prokesch, 14. 1. 1856, AGKK, I, 3 (wie Anm. 7), Nr. 128.

108 Vgl. Reculot an Walewski, 7. 1. 1856, AMAE (wie Anm. 10), CP Hanovre, 74, f. 76.

109 Vgl. Walewski an Bourqueney, 9. 12. 1855, AMAE (wie Anm. 10), CP Autriche, 461, f. 209-211; Walewski an Persigny, 3. 1. 1856, AMAE (wie Anm. 10), CP Angleterre, 704, f. 9 f.; Desprez an Thouvenel, 4. 1. 1856, AN (wie Anm. 3), 192 MI, 5, Nr. 101 bzw. Louis Thouvenel, Pages de l'histoire du Second Empire. D'après les papiers de M. [Edouard Antoine] Thouvenel, 1854-1856, Paris 1903, S. 196-200; Méneval an Walewski, 30. 12. 1855, AMAE (wie Anm. 10), CP Bavière, 234, f. 72-75; Ferrière-le-Vayer an Walewski, 30. 12. 1855, AMAE (wie Anm. 10), CP Wurtemberg, 79, f. 313-315. - Zu Beust/Pfordten vgl. Baumgart, Friede (wie Anm. 4), S. 91-93. 
Im Grunde hatte man an der Seine die Bessarabien-Frage von Anfang an als negoziabel betrachtet: "C'est l'Autriche qui [...] a introduit cette condition; on pourrait y renoncer ${ }^{110}$. . Entsprechende Andeutungen hatte Napoleons Mittelsmann Seebach Ende Dezember nach Petersburg mitgenommen ${ }^{111}$. Das widersprach flagrant der Konzeption eines ohne Abstriche und Diskussion zu akzeptierenden oder zu verwerfenden Ultimatums, zu der Frankreich sich feierlich bekannt hatte ${ }^{112}$. Schon das kaiserliche Handschreiben vom 22. November 1855 hätte eigentlich in London, das nur unter dieser Voraussetzung sein Plazet zur Friedensinitiative seiner kontinentalen Partner gegeben hatte, die Alarmglocken auslösen müssen: war darin doch der Erwartung Ausdruck verliehen, Rußland werde, wenn man dem österreichischen Programm folge, genötigt sein, »à proposer des conditions de paix équitables $«{ }^{113}$.

Alexanders Außenminister, Karl Robert Graf von Nesselrode, legte am 5. Januar 1856 einen Gegenvorschlag vor, der, was Bessarabien betraf, die Grenzberichtigung durch Petersburgs Zustimmung zur Rückgabe der besetzten türkischen $»$ Festungen ${ }^{114}$ und "Gebiete ersetzte, von Kars nebst Umland also, und alle Details an die Friedenskonferenz verwies. Seebach, der in Paris das russische Angebot spätestens am ersten Tag des Kriegsrats mitgeteilt hatte ${ }^{115}$, noch inoffiziell natürlich, bekräftigte es am 13. Januar und versicherte, an die schlichte Annahme des österreichischen Ultimatums sei nie und nimmer zu denken ${ }^{116}$. Auch ohne diesen Kommentar kamen die russischen Modifikationen einer Ablehnung gleich und hatte die ohnehin schwache Hoffnung auf eine bedingungslose Kapitulation des Zarenreichs einen schweren Dämpfer erhalten. Noch am Tag der entscheidenden Ministerratssitzung, dem 15. Januar, war Napoleon überzeugt: "L'ultimatum ne sera pas accepté ${ }^{117}$."

Wie aber hatte der Präsident des Kriegsrats in den vorangegangenen Tagen auf die russischen Eröffnungen reagiert? Jetzt, wenn überhaupt jemals, hätte der Kriegsrat um einen österreichischen Vertreter erweitert oder bis $\mathrm{zu}$ dessen Eintreffen vertagt werden müssen, je nachdem, ob die Wahl auf Hübner oder den Militärbevollmächtigten vom Vorjahr fiel, auf Franz Graf Folliot de Crenneville. Dessen Berufung nach Paris hätte als das militärische Gegenstück zur Übersendung des Ultimatums nach Petersburg ihren Eindruck kaum verfehlt. Und jetzt, wenn überhaupt jemals, hätte der zurückgestellte Dritte Tagesordnungspunkt

110 Morny an Walewski, [26. 11. 1855], AMAE (wie Anm. 10), MD France, 2117, f. 70.

111 Vgl. V. Esterházy an Buol, 7. und 12. 1. 1856, AGKK, I, 3 (wie Anm. 7), Nr. 103, 120; Reculot an Walewski, 7. 1. 1856, AMAE (wie Anm. 10), CP Hanovre, 74, f. 75 f.

$112 \mathrm{Vgl}$. österreichisch-französisches Memorandum, 14. 11. 1855, AGKK, I, 3 (wie Anm. 7), Nr. 33; Walewski an Persigny, 28. 11. 1855, AMAE (wie Anm. 10), CP Angleterre, 703, f. 117.

113 Napoleon an Victoria, 22. 11. 1855, Martin, Life (wie Anm. 17), S. 525.

114 Benedetti an Thouvenel, 12. 1. 1856, in: Thouvenel, Pages (wie Anm. 109), S. 204.

115 Also zwei Tage vor Eingang der russischen Antwort. Walewski bezog sich gegenüber Napoleon schon am 10. Januar auf sla substitution que propose la Russie de Kars à la Bessarabie«, Familienarchiv Walewski, C 1, p. 60.

116 Vgl. Walewski an Persigny, 14. 1. 1856, AMAE (wie Anm. 10), CP Angleterre, 704, f. 38 bis f.; Hübner an Buol, 19. 1. 1856, AGKK, I, 3 (wie Anm. 7), Nr. 146; Cambridge an Clarendon, 15. 1. 1856, in: George Duke of Cambridge, A Memoir of his Private Life based on the Journals and Correspondence of His Royal Highness. Vol. 1: 1819-1871. Ed. by Edgar Sheppard, London [u. a.] 1906, S. 167.

117 Fortoul, Journal (wie Anm. 35), S. 200. 
behandelt werden müssen, sei es auch allein im Hinblick darauf, durch die Ankündigung einer Rheinarmee und des bevorstehenden militärischen Schulterschlusses mit Wien ${ }^{118}$ den Druck auf Rußland und Preußen soweit zu steigern, daß am 18. Januar eben keine Ablehnung des Ultimatums erfolgen würde.

Nichts dergleichen geschah. Im Gegenteil: Napoleon reagierte auf die russischen Vorschläge, indem er unverzüglich - am 12. Januar ${ }^{119}$ - jenes Schreiben an Victoria verfaßte, das Friedensverhandlungen auf dieser Basis als höchst wünschenswert bezeichnete, dem bessarabisch-kleinasiatischen Tauschhandel das Wort redete und durch die Blume zu verstehen gab, daß er, der Kaiser, den Kampf nicht fortsetzen wolle: "Mais [...] autour de moi au contraire j'ai dit qu'il fallait continuer la guerre ${ }^{120}$." Andere Alternativen zum Frieden als die "sehr traurige ${ }^{121}$, sich für die geringfügige Differenz zwischen Österreichs Forderung und Rußlands Gegengebot schlagen zu müssen, für die ominösen bessarabischen Heidegebiete, Alternativen, wie sie das Handschreiben vom 22. November 1855 noch zur Diskussion gestellt hatte - sie zog er nun nicht mehr in Betracht. $\mathrm{Zu}$ übermächtig war sein Friedensbedürfnis ${ }^{122}$, zu verlockend die ihm von Nesselrode eröffnete Chance, das Präsidium des Kriegs- mit dem eines Vorfriedenskongresses zu vertauschen ${ }^{123}$. - Welch hohe Bedeutung der Kaiser dem russischen Schritt beimaß, erhellt daraus, daß er sich diesmal, anders als in den Verhandlungen über das österreichische Ultimatum ${ }^{124}$, nicht allein auf seinen Außenminister verließ. Der Monarchenbrief an Victoria ging hinter dem Rücken von Alexandre Comte de Walewski nach Windsor $\mathrm{ab}^{125}$, während sein Intimfeind, Jean Fialin Comte de Persigny, aus den Tuilerien Weisung erhielt, Clarendon gegenüber ins gleiche Horn zu stoßen: Frankreichs öffentliche Meinung fordere, quer durch alle Stände, die Armee nicht ausgenommen, von Tag zu Tag gebieterischer den Frieden ${ }^{126}$.

Ohne Walewski auch nur die Zeit zu geben, eine Abschrift der russischen Note zu nehmen, ließ Napoleon sie zusammen mit einem eigenhändig überarbeiteten Plädoyer zugunsten des Petersburger Projekts im Foreign Office vorle-

118 "Si l'Autriche était franchement avec nous [...] quel coup ne porterait-on pas à la Russie par la simple annonce du rétablissement de la Pologne. « Gutachten Canroberts, 16. 1. 1856, PRO (wie Anm. 5), WO 33/2 B, S. 33.

119 Vgl. Cowley an Clarendon, 13. 1. 1856, AGKK, III, 4 (wie Anm. 1), Nr. 339.

120 Napoleon an Victoria, 14. 1. 1856, in: Victoria, Letters (wie Anm. 18), S. 163.

121 Ebd., S. 162. - Baroche resümierte nach der Ministerratssitzung vom 15. Januar: "L'Empereur et tous les ministres sont d'accord sur ce point [...] qu'il serait insensé de continuer la guerre. " Jean Maurain, Un bourgeois français au dix-neuvième siècle, Baroche, ministre de Napoléon III, d'après ses papiers inédits, Paris 1936, S. 166.

122 Um den 10. Januar herum hatte er geäußert: "Je donnerais quatre doigts de la main pour signer la paix en ce moment. «C. Damrémont an Thouvenel, 18. 1. 1856, AN (wie Anm. 3), 192 MI, 5, Nr. 11 bzw. Thouvenel, Pages (wie Anm. 109), S. 191.

$123 \mathrm{Vgl}$. Cambridge an Clarendon, 15. 1. 1856, in: Cambridge, Memoir (wie Anm. 116), S. 167.

124 "Je suis lié (entre nous) sans le savoir; vous n'avez nullement appelé mon attention sur ce fait que les préliminaires de paix seraient signés avant qu'on ne soit d'accord sur les conditions particulières!“ Napoleon an Walewski, 18. 1. 1856, Acte (wie Anm. 35), Nr. 2750.

125 Napoleon: »to prevent the affair falling into official hands«. Cowley an Clarendon, 13. 1. 1856, AGKK, III, 4 (wie Anm. 1), Nr. 339.

126 Vgl. Clarendon an Victoria, 16. 1. 1856, ebd., Nr. 351. Persignys Antwort in Thouvenel, Pages (wie Anm. 109), S. 206-210. 
gen $^{127}$. Dort und in Downing Street war man für Konzessionen in Sachen Bessarabien indes nicht zu haben, obwohl der französische Botschafter unverhüllt mit dem Bruch der Allianz drohte: "Les relations entre les deux Gouv ${ }^{\text {ts }}$ n'ont jamais été aussi tendues qu'aujourd'hui ${ }^{128}$, "Das Kabinett beschloß daraufhin, zunächst den Achtzehnten und Rußlands letztes Wort abzuwarten. Dieser Bescheid, in der Form konziliant, da dilatorisch, lief in der Sache auf eine Abfuhr hinaus. Nahm man im Außenministerium an der Sängerbrücke das Ultimatum noch an, so waren die Gegenvorschläge ohnehin überholt; blieb es bei den Modifikationen, dann bedeutete das den diplomatischen Bruch mit Österreich, der die Position der Seemächte stärken und sie in die Lage versetzen würde, Abstriche an der bessarabischen Gebietsforderung verweigern zu können, sie mit Rücksicht auf den habsburgischen Partner sogar verweigern zu müssen. Schließlich hatte Hübner angekündigt, Wien werde sich in dieser Frage jeglicher Konzession saufs äußerste ${ }^{129}$ widersetzen.

Buol freilich wußte, daß der Nichtkombattant dem einhelligen Wunsch der Kriegführenden letztlich bloß zum eigenen Schaden im Weg stehen würde, da das Gespenst eines über Österreichs Kopf hinweg geschlossenen Friedens leicht Realität werden konnte ${ }^{130}$. - Deshalb durfte man den Ballhausplatz einstweilen links liegen lassen und mußte es dem Quai d'Orsay vorrangig um Englands Zustimmung zum Bessarabien-Plan zu tun sein. Wie sie zu erreichen sei, hatte Walewski seinem Souverän am 10. Januar 1856 dargelegt, jenem Tag, an dem das Kompensationsgeschäft unter seiner Feder Gestalt angenommen hatte: Zunächst gelte es, den Bruch zwischen Wien und Petersburg abzuwarten, danach die russischen Gegenvorschläge gemeinsam mit London zu prüfen ${ }^{131}$. Das entsprach genau dem Kurs, den auch Napoleon zu verfolgen gedachte ${ }^{132}$. Walewskis nächster Schritt sah folgendermaßen aus: Das britische Kabinett werde weder sich selbst noch der Öffentlichkeit verbergen können, wie zweitrangig die Forderungen seien, um derentwillen der Krieg noch fortgesetzt würde. "Une fois la question placée sur ce terrain, la force des choses en amènera la solution, d'autant plus qu'il y aura certainement en Europe un mouvement en faveur de la paix, dont le contrecoup arrivera jusqu'à Londres ${ }^{133}$." Das ist im Kern dieselbe Dro-

127 Vgl. Walewski an Persigny, No. 7 und [11], 14. 1. 1856, AMAE (wie Anm. 10), CP Angleterre, f. 41, 38 bis f.; ferner Clarendon an Cowley, 15. 1. 1856, AGKK, III, 4 (wie Anm. 1), Nr. 348.

128 Clarendon an Victoria, 16. 1. 1856, AGKK, III, 4, Nr. 351; vgl. Palmerston an Clarendon, 16. 1. 1856, ebd., Nr. 352.

129 Hübner an Buol, 19. 1. 1856, AGKK, I, 3 (wie Anm. 7), Nr. 145; vgl. Bourqueney an Walewski, 21. 1. 1856, AMAE (wie Anm. 10), CP Autriche, 463, f. 97 f.

130 Vgl. Buol an Hübner, 12. 1. 1856; Buol an V. Esterházy, 14. 1. 1856, AGKK, I, 3 (wie Anm. 7), Nr. 117, 126; Clarendon an Cowley, 15. 1. 1856, AGKK, III, 4 (wie Anm. 1), Nr. 348.

131 Vgl. Walewski an Napoleon, 10. 1. 1856, Familienarchiv Walewski, C 1, p. 60-62; Walewski an Persigny, 10. 1. 1856, AMAE (wie Anm. 10), CP Anglerterre, 704, f. 26-28.

132 Vgl. Fortoul, Journal (wie Anm. 35), S. 200 (zum 15. 1. 1856); Maurain, Bourgeois (wie Anm. 121), S. 166 (zum 15. 1. 1856); Hübner an Buol, 13. 1. 1856, AGKK, I, 3 (wie Anm. 7), Nr. 124.

133 Walewski an Napoleon, 10. 1. 1856, Familienarchiv Walewski, C 1, p. 62. - War Walewski jetzt "plus russe que les Russes«, so hatte er sich im Herbst 1855 "plus autrichien que l'Autriche« gezeigt (Napoleon an Walewski, 18. 1. 1856, Acte - wie Anm. 35 Nr. 2750). Sein britischer Kollege war von ihm belehrt worden: "J'ai toujours eu la plus grande confiance dans le bon sens du peuple Anglais et si on affichait dans toute 
hung, die in diesen Tagen ein russischer Diplomat vernehmen ließ - verweigere Palmerston wegen Bessarabien Rußland den Frieden, so werde man an die öffentliche Meinung Europas appellieren: der ganze Kontinent und selbst die "aufgeklärten Männer Englands « ${ }^{134}$ würden dann kaum umhin können, im britischen Kabinett das Friedenshindernis zu erkennen. Frankreich hätte also das Pressionssystem, den >Bannstrahl Europas‘, nicht mehr gegen den Kriegsgegner, sondern gegen den bockbeinigen Verbündeten gerichtet und sich dabei in der pikanten Lage befunden, mit dem Zarenreich vielleicht nicht Hand in Hand zu arbeiten, aber jedenfalls am selben Strang zu ziehen.

Rußlands einfache und vorbehaltlose Annahme des Ultimatums, die in Paris am 17. Januar bekannt wurde, hat der Entente cordiale diese Belastungsprobe erspart. Es folgte aber sogleich eine weitere. Denn mit der ihm eigenen Zähigkeit hielt Napoleon am Programm seines Handschreibens vom 14. Januar fest: Das Zarenreich sollte Bessarabien, das es mit seiner Zustimmung zu den Friedensbedingungen inzwischen preisgegeben hatte, bis auf die Donaufestungen behalten dürfen, dagegen Kars zurückgeben und sich zur Entfestigung der Åland-Inseln verpflichten. Neu war lediglich, daß dies alles Bestandteil des Vorfriedens sein sollte. Die Präliminarien würden mithin »der Friede selbst ${ }^{135}$ sein, die Konferenzen ihn nur mehr ratifizieren und, statt der Frage von Krieg und Frieden, allenfalls solche von zweitrangiger Bedeutung zu entscheiden haben ${ }^{136}$.

Hat Napoleon diese Lösung bereits vorgeschwebt, als er in der Ministerratssitzung vom 15. Januar die erwartete Abweisung des Ultimatums geradezu als eine glückliche Fügung bezeichnete? Glücklich deshalb, weil sie die Chance bot, das Problem der >englischen ‘ Spezialbedingungen zu entschärfen: "Alors le rideau tombant sur un premier acte de la négociation, on pourra reprendre l'cuvre sur des bases nouvelles et non équivoques ${ }^{137}$." Oder ging die Konzeption eines sdefinitiven Vorfriedens auf den früheren Außenminister Edouard Drouyn de Lhuys zurück ${ }^{138}$, der stets darauf gedrungen hatte, den Krieg zu beenden, sobald Frankreichs eigentliches Ziel erreicht sei, die Zerstörung der Heiligen Allianz? Wie auch immer: Der Kaiser wollte auf diese Weise den Friedensprozeß unum-

l'Angleterre les conditions auxquelles l'Autriche propose de faire la paix, je voudrais savoir combien il y aurait de voix contre?! pas une sur vingt. "Walewski an Clarendon, 19. 11. 1855, BLO (wie Anm. 10), Clarendon Dep., c. 35, f. 154. In seiner Rechtfertigung beanspruchte der Außenminister nicht direkt, seine Politik sei splus napoléonienne que Napoléon', aber: ")'ai toujours eu la conviction que j'agissais absolument dans le sens de vos vues intimes et [...] de vos arrièrepensées. «Walewski an Napoleon, 18. 1. 1856, Familienarchiv Walewski, C 1, p. 69.

134 Barrot an Walewski, 14. 1. 1856, AMAE (wie Anm. 10), CP Belgique, 40, f. 71.

$135 \mathrm{Vgl}$. Napoleon an Walewski, 18. 1. 1856, Acte (wie Anm. 35), Nr. 2750.

136 Vgl. Walewski an Napoleon, 18. 1. 1856, Gaston Raindre, Les papiers inédits du Comte Walewski. Souvenirs et correspondance (1855-1868), in: La Revue de France 5/1 (1925), S. 493.

137 Fortoul, Journal (wie Anm. 35), S. 200.

138 Vgl. Drouyn de Lhuys an Napoleon, 17. 1. 1856, Raindre, Papiers (wie Anm. 136), S. 491; >Letter [...] on M. Drouyn de Lhuys's opinions \& behaviours', [August 1855], Oriental Question (wie Anm. 5), XVI, RA (M), G 37/67; ferner Chimay an Ernst II., 22. 8. 1855, StAC (wie Anm. 4), LA A 7180, f. 40-45.

139 »[...] de mettre en demeure la Russie de se prononcer avant la négociation sur l'acceptation des conditions dont on lui fait connaître la teneur.« Walewski an Napoleon, 18. 1. 1856, Familienarchiv Walewski, C 1, p. 71; vgl. Walewski an Persigny, 22. und 25. 1. 1856, AMAE (wie Anm. 10), CP Angleterre, 704, f. 88, 116-120. 
kehrbar machen, um nicht noch auf den letzten Metern an Englands Sonderwünschen zu scheitern. Denn Londons Forderung, die Spezialbedingungen vor Unterzeichnung der Präliminarien nach Petersburg mitzuteilen, hatte aus französischer Sicht den Beigeschmack eines zweiten Ultimatums ${ }^{139}$, dessen Vorlage von Österreich als Abspringen vom vereinbarten Modus procedendi empfunden und dahingehend interpretiert werden konnte, nun seinerseits aller Verpflichtungen los und ledig zu sein. Die Westmächte wären, wie einer ihrer fähigsten Diplomaten befürchtete ${ }^{140}$, genötigt gewesen, den Krieg unter den denkbar ungünstigsten Vorzeichen fortzusetzen.

Gepeinigt vom Alpdruck einer nichts weniger als 'glänzenden`Isolation, beugten sich die Briten im Hinblick auf die Spezialbedingungen weitgehend den Vorstellungen des französischen Partners ${ }^{141}$. Paris wiederum ließ die Idee eines >definitiven` Präliminarfriedens fallen, weil dessen Dreh- und Angelpunkt, der Einsatz Bessarabiens als Handelsobjekt, dieselbe verhängnisvolle Entwicklung auszulösen drohte wie die englischen Vorstellungen zum Fünften Punkt ${ }^{142}$. Daran aber konnte Napoleon um so weniger gelegen sein, als er mit einigem Recht hoffen durfte, den Krieg auf ein totes Gleis geschoben zu haben.

\section{Die sSchlacht ohne Krieg}

Der wohl am 18./19. Januar von Napoleon ausgearbeitete Feldzugsplan, für den er die Mehrheit des Kriegsrats hinter sich wußte ${ }^{143}$, genügte vordergründig dem selbstgestellten Anspruch, retwas Bedeutendes auszurichten «: Auf der Krim sollten schließlich rund eine Drittelmillion ${ }^{144}$ Russen und Alliierte in der größten Militäraktion seit der Völkerschlacht von Leipzig gegeneinander antreten. Das verhieß wesentlich mehr éclat als eine noch so wirksame Seeblockade. Zudem hätte diese Form des sbeschränkten Krieges keinen Ausweg aus der Sackgasse Krim eröffnet, in der die Verbündeten bei hohen Kosten und ohne erkennbaren Nutzen ausharren mußten. »L'embarquement devant l'ennemi [...] équivaudrait moralement à une défaite « ${ }^{145}$, begründete der Kaiser denn auch seine Entscheidung für die Krim und beugte sich damit, zu Cowleys unverhohlener Befriedigung, englischen Argumenten ${ }^{146}$, gegen die er sich lange taub gestellt hatte: Rußlands

140 Frankreichs Gesandter in Wien, François-Adolphe Comte de Bourqueney: «L'Autriche [...] se posera peut être entre les deux camps et, avant quinze jours, elle aura passé dans l'autre. La Russie ne préférera pas la paix à la chance plus qu'assurée de reconquérir l'Autriche. « Bourqueney an Walewski, 25. 1. 1856, AMAE (wie Anm. 10), CP Autriche, 463, f. 121.

141 Vgl. Palmerston an Victoria, 26. 1. 1856, AGKK, III, 4 (wie Anm. 1), Nr. 400; Denkschrift Prinz Alberts, 25. 1. 1856, ebd., Nr. 394; Napoleon an Walewski, [19. 1. 1856], AMAE (wie Anm. 10), MD France, 2116, f. 434.

142 Vgl. Bourqueney an Walewski, 21. 1. 1856, AMAE (wie Anm. 10), CP Autriche, 463, f. 97 f.; Walewski an Bourqueney, 22. 1. 1856, ebd., f. 99.

143 Vgl. Aufzeichnung J. Napoleons, 16. [!] 1. 1856, AN (wie Anm. 3), 400 AP, 119, Nr. 6; Aufzeichnung Cambridges, 18. 1. 1856, AGKK, III, 4 (wie Anm. 1), Nr. 366.

144 Vgl. Baumgart, Kriegsrat (wie Anm. 1), S. 225.

145 Denkschrift Napoleons, 20. 1. 1856, PRO (wie Anm. 5), WO 33/2 B, S. 54.

146 Vgl. Persigny an Napoleon, 30. 10. 1855, AMAE (wie Anm. 10), PA Walewski, 24, 
Widerstandswille und sein Prestige in Deutschland würden durch eine sangund klanglose Räumung gestärkt, die Chance eines raschen Friedensschlusses wäre vertan.

Insofern machte diese Operation nicht nur militärisch Sinn, als die einfachste und aussichtsreichste Möglichkeit zur Erzwingung eines russischen Rückzugs, sondern auch politisch. Letzteres allerdings in weit geringerem Maße als andere Optionen: "We should be doing more good by driving the Russians out of the Countries South of the Caucasus than by driving them out of Perekop ${ }^{147}$.《

Aus britischer Sicht war das Krimunternehmen ein unerläßliches Vorspiel, sozusagen die Pflicht vor der Kür ${ }^{148}$. Ihm sollte eine Reihe weiterer Feldzüge an Rußlands Peripherie folgen, mit deren erfolgreichem Abschluß man die Hoffnung verband, den Frieden statt zu Österreichs Bedingungen zu den eigenen schließen zu können ${ }^{149}$. Andernfalls hätte »im Frühjahr $1857 \aleph^{150}$, wie der wohlunterrichtete belgische König glaubte, der Angriff auf das russische Zentrum begonnen, unter Beteiligung Österreichs und vermutlich in Polen.

Napoleon hingegen, für den sich der Schauplatz des Dramas spätestens seit den russischen Friedensvorschlägen auf die diplomatische Bühne verlagert hatte, schwieg sich über die weiteren Akte des Kriegstheaters beharrlich aus. Dem Sekretär des Kriegsrats, Adolphe Niel, blieb es vorbehalten, eine grundsätzliche Feststellung zu treffen, die sich keineswegs bloß auf die Ouvertüre bezog: "Ce qu'on a en vue en continuant la lutte, ce n'est [...] pas d'enlever à la Russie quelque portion importante de son territoire, c'est seulement de la forcer à demander la paix ${ }^{151}$."

Für Frankreich hatte die Krim-Kampagne nicht mehr und nicht weniger zum Ziel, als eine ungestörte und ehrenvolle Räumung zu sichern; allenfalls das dann zur Gänze eroberte Sevastopol' wäre möglicherweise als Faustpfand zurückbehalten worden, wie es schon ein früherer Feldzugsplan vorgesehen hatte ${ }^{152}$. Anlaß zu einem Hochschrauben der Friedensbedingungen in nennenswertem, für Rußland schmerzhaftem Maße konnte und sollte sie nicht sein. Jede andere Option jedoch - Finnland, Georgien, Bessarabien, selbst Nikolaev — hätte militärische Tatsachen geschaffen, die, darauf hätte schon London bestanden ${ }^{153}$, in politische Forderungen umgemünzt worden wären. Diese hätten den Friedensprozeß ungleich stärker gehemmt und gefährdet als die leidigen bessarabischen Heidegebiete. Die Gunst der Stunde, die das Zarenreich durch die Einnahme von Kars mit den Seemächten hatte gleichziehen lassen, die es ihm ermöglicht hatte, ohne Gesichtsverlust Friedensverhandlungen aufzunehmen - diese Gunst der Stunde wäre vertan gewesen, der Krieg hätte bis zum nächsten Patt

f. 50-54, 57-62; Clarendon an Cowley, 16. 11. 1855, AGKK, III, 4 (wie Anm. 1), Nr. 161; Cowley an Clarendon, 9. 1. 1856, ebd., Nr. 323.

147 Palmerston an Clarendon, 23. 11. 1855, AGKK, III, 4 (wie Anm. 1), Nr. 192.

148 »This all important preliminary step seems to be omitted in all our calculations [...] upon the campaigns of next year.« Clarendon an Stratford, 28. 12. 1855, ebd., Nr. 295.

$149 »[$...] by Christimas 56«. Palmerston an Clarendon, 22. 11. 1855, ebd., Nr. 186.

150 Barrot an Walewski, 8. 1. 1856, AMAE (wie Anm. 10), CP Belgique, 40, f. 34.

151 Gutachten Niels, 17. 1. 1856, PRO (wie Anm. 5), WO 33/2 B, S. 40.

152 Vgl. Napoleon an Walewski, 14. 9. 1855, in: Rousset, Histoire (wie Anm. 1), S. 404-407. - "Pourquoi s'en aller, une fois maîtres de toute la Crimée facile à défendre à Pérécop? « Auf́zeichnung J. Napoleons, 16. [!] 1. 1856, AN (wie Anm. 3), 400 AP, 119, Nr. 6.

153 Vgl. Palmerston an Clarendon, 16. 10. 1855, AGKK, III, 4 (wie Anm. 1), Nr. 92. 
oder gar bis zum bitteren Ende fortgesetzt werden müssen. Wie eine seiner $\ddot{A}$ ußerungen zu Seebach bezeug ${ }^{154}$, hat Napoleon das sehr genau gesehen.

Vor diesem Hintergrund dürfte seine Entscheidung für das ungeliebte Krimunternehmen, die an der Themse entsprechend überraschte ${ }^{155}$, nicht allein der Einsicht in die >moralische Notwendigkeit dieses letzten Hurras, sondern auch und gerade der Absicht zuzuschreiben sein, andere Alternativen zu verhindern - Großoperationen im Baltikum und östlich des Schwarzen Meeres, die den von Frankreich ersehnten Frieden um rein britischer Interessen willen in Frage zu stellen drohten. Paris konnte kaum daran gelegen sein, zur See »das jetzt erdrückende Übergewicht Englands « ${ }^{156}$ noch verstärkt oder zu Lande jedwede Reibungsfläche zwischen London und Petersburg durch ein System neugeschaffener Pufferstaaten ${ }^{157}$ beseitigt zu sehen. Und wirklich: Mit dem militärisch unanfechtbaren Argument, eine Zersplitterung der Kräfte sei von Übel, suchte der Kaiser die Ostsee-Expedition zu einem Handstreich zu degradieren und gelang es ihm, die Verschiebung des Kaukasus-Feldzugs durchzusetzen ${ }^{158}$.

Dergestalt ein gutes Stück in die Zukunft entrückt, war der >große‘ Krieg von einer hoch determinierten Wahrscheinlichkeit zur vagen Möglichkeit abgesunken, während der Vorstoß auf Simferopol' unversehens vom Seiten- zum Hauptstück avanciert war. Wo Buol auf >den Krieg ohne Schlacht ‘ vertraute, da hatte Napoleon sdie Schlacht ohne Krieg، im Sinn: nicht als Auftakt, sondern als Schlußakt.

\section{Ein `Scheinkriegsrat $<$ Napoleons III.}

Wie ernst war es dem Kaiser nun mit diesem letzten Hurra? - Zur selben Zeit, da er die Umbefestigung des Nordforts von Sevastopol' in seinen Feldzugsplan aufnahm, befahl sein Kriegsminister, Marschall Jean-Baptiste Vaillant, die Quarantäne-Batterie und Fort St. Nikolaus zu schleifen ${ }^{159}$. Letzteres, "ein giganti-

$154 »[. .$.$] qu'il y avait deux moyens de terminer une grande guerre: ou bien par l'épuise-$ ment complet de l'une des deux parties, ou bien par une égalité de position laissant l'honneur sauf.« Etude Diplomatique (wie Anm. 77), S. 381.

155 Vgl. Tagebucheintragung Victorias, 22. 1. 1856, AGKK, III, 4 (wie Anm. 1), Nr. 379.

156 So urteilte der Kaiser ein Jahr nach Kriegsende, Poschinger, Achtundvierziger (wie Anm. 51), S. 155. Anfang Januar 1856 knüpften sich in seiner Umgebung an den Gedanken des maritimen Gleichgewichts Spekulationen über einen Separatfrieden, vgl. C. Damrémont an Thouvenel, 18. 1. 1856, AN (wie Anm. 3), 192 MI, 5, Nr. 11 bzw. Thouvenel, Pages (wie Anm. 109), S. 191.

157 "...] des arrangemens si ingénieusement combinés qu'ils permettraient peut être à l'Angleterre de se passer de nous.« Bourée an Walewski, 31. 10. 1855, AMAE (wie Anm. 10), CP Perse, 25, f. 248.

158 Während Napoleon für den Angriff auf Kronstadt eine anglo-französische Flotte von 172 Einheiten vorsah, forderte London deren 420, vgl. Denkschrift Napoleons, 20. 1. 1856, PRO (wie Anm. 5), WO 33/2 B, S. 53; Clarendon an Cowley, 2. 2. 1856 (Anlage 2), AGKK, III, 4 (wie Anm. 1), Nr. 419. - Zur Diskussion über die Kaukasus-Operation vgl. Baumgart, Kriegsrat (wie Anm. 1), S. 229 f. und die einschlägigen Quellen in AGKK, III, 4 (wie Anm. 1).

159 Vgl. Denkschrift Napoleons, 20. 1. 1856, PRO (wie Anm. 5), WO 33/2 B, S. 56; Vaillant an Pélissier, 19. 1. 1856, SHAT (wie Anm. 5), G 1, 48. 
sches Werk « ${ }^{160}$ mit einer Front von 425 Metern, hatten die Russen vor ihrem Rückzug desarmiert und teilweise vermint, ohne daß es zur Sprengung gekommen wäre. Napoleon wiederum, der zu diesem Zeitpunkt bereits erwogen hatte, Sevastopol' bis zur endgültigen Räumung der Krim als alliierte Festung zu nutzen, hatte jede weitere Zerstörung der Verteidigungsanlagen ausdrücklich untersagt $^{161}$. Warum hätte er sie im Januar 1856 plötzlich genehmigen sollen? Auch wenn es keine anglo-französische Festung Sevastopol' geben sollte und es sich gleich blieb, ob das Nordfort oder Fort St. Nikolaus die Einschiffung der Verbündeten deckte, so bedeutete es doch ein unnötiges Risiko, hierfür Befestigungen einzuplanen, von denen niemand wußte, wann und in welchem Zustand sie den Alliierten in die Hände fallen würden, während man wesentliche Teile der bereits verfügbaren Werke zur Demolierung freigab.

Der Kriegsminister hatte im September 1855 entschieden dafür plädiert, Sevastopol' erst nach Beendigung des Krim-Feldzugs zu schleifen ${ }^{162}$. Ganz gewiß zählte er nicht zu denen, die Rußlands Brückenkopf im Schwarzen Meer unverzüglich dem Erdboden gleichgemacht sehen wollten: ‘Mort la bête, mort le venin $^{163}$. Denn nur widerwillig und auf Geheiß des Kaisers hatte er im folgenden Monat dem britischen Wunsch willfahrt ${ }^{164}$, wenigstens die Docks sofort zu zerstören.

Da mittlerweile, im Januar 1856, gegen die Sprengung sogar politische Bedenken ins Feld geführt wurden ${ }^{165}$, wird Vaillant kaum ohne das Einverständnis seines Souveräns gehandelt haben, als er seine Ordre am 29. Januar bestätigte. Solange ihre Flotten den Pontus beherrschten, durften die Westmächte seeseitige Verteidigungsanlagen für entbehrlich halten ${ }^{166}$. Deren Schleifung aber hätte warten können, es sei denn, Napoleon hätte statt eines möglicherweise langen und wechselvollen Waffengangs die Rückgabe der Festung an Rußland im Auge gehabt, mit einem Wort: den Frieden.

Als im März 1856 das Ende des Waffenstillstands heranrückte, es indes zweifelhaft schien, ob der Friedensvertrag rechtzeitig unterschriftsreif sein würde, da gab Napoleon immer unverhüllter zu verstehen, ein französischer Beitrag zur Verwirklichung des Feldzugsplans sei nicht zu erwarten ${ }^{167}$. Der in der Tat hohe Krankenstand der Orient-Armee, auf den er sich berief, wurde jenseits des $\ddot{A}$ melkanals für ein vorgeschobenes Argument gehalten ${ }^{168}$. Den Hinweis, die fran-

160 Pélissier an Vaillant, 15. 9. 1855, SHAT (wie Anm. 5), G 1, 28.

161 Vgl. Napoleon an Walewski, 14. 9. 1855, in: Rousset, Histoire (wie Anm. 1), S. 404-407; Clarendon an Victoria, 16. 9. 1855, AGKK, III, 4 (wie Anm. 1), S. 107, Anm. 1.

162 Vgl. Denkschrift Vaillants 'Sébastopol. Faut-il conserver ou démolir les fortifications encore existantes?‘, 14. 9. 1855, SHAT (wie Anm. 5), G 1, 28; auch verfilmt in Oriental Question (wie Anm. 5), XVII, RA (M), G 38/66.

163 Thouvenel an Walewski, 27. 9. 1855, SHAT (wie Anm. 5), G 1, 29.

164 Vgl. Vaillant an Cowley, 17. 10. 1855, ebd., 31, Nr. 28.

165 Vgl. Pélissier an Vaillant, 22. 1. 1856, ebd., 57/3. Daß Vaillant sich rückversichert hatte, geht aus seiner Antwort vom 29. Januar hervor, ebd., 37, Nr. 35: "Quant à faire de cette destruction [...] l'objet d'une stipulation diplomatique, $c^{\prime}$ est repoussé ici.«

166 Vgl. Aufzeichnung Drouyn de Lhuys', [Anfang Oktober 1854], AMAE (wie Anm. 10), CP Angleterre, 697, f. 137.

167 Vgl. Clarendon an Palmerston, 7. und 26. 3. 1856, AGKK, III, 4 (wie Anm. 1), Nr. 512, 575.

168 Vgl. Palerston an Clarendon, 11. 3. 1856, ebd., Nr. 526. - Wenn im April 1856 die Zahl der Dienstunfähigen bei der französischen Expeditionsarmee $28 \%$ betrug, gegenüber knapp $8 \%$ bei den Engländern (vgl. Baumgart, Friede - wie Anm. 4 - S. 136), dann wohl auch deshalb, weil ausschließlich die Gesunden nach Frankreich eingeschifft 
zösische Nation werde eine Fortsetzung des Krieges eher England als ihm, dem Kaiser, zur Last legen ${ }^{169}$, mußte man schon ernster nehmen. Clarendon wenigstens bezweifelte nicht, daß die Alternative zum Friedensschluß der Bruch der Entente cordiale sein könnte, schlimmer noch, eine europäisch-amerikanische Koalition gegen das Inselreich ${ }^{170}$. Als Kongreßbevollmächtigter zeigte er folglich eine zwar feste, doch keineswegs starre Haltung. Freie Hand, zum Besten Englands und im Interesse der Allianz hinter Palmerstons Maximalforderungen zurückzugehen, hatte er sich in richtiger - pessimistischer - Einschätzung des französischen Kriegswillens beizeiten einräumen lassen ${ }^{171}$.

Nach alledem hätte er, in Abwandlung seines Urteils über die Wiener Konferenzen $^{172}$, mit gutem Grund von einem >Scheinkriegsrat‘ sprechen können. Damals, im Frühjahr 1855, hatte Napoleon beträchtlichen Wert auf eine frühzeitige Abstimmung der anglo-französischen und österreichischen Operationen gelegt ${ }^{173}$, wohl wissend, daß ohne aktive Mitwirkung des Kaiserstaates der >große Krieg undenkbar war, in Deutschland so gut wie in Polen. Diesmal hingegen hatte er Wien aus der militärischen Diskussion völlig ausgeklammert. Nicht etwa deshalb, weil der 'große Krieg grundsätzlich als Nationalitätenkrieg und damit gegen Wien hätte geführt werden müssen; nicht etwa deshalb, weil Buol auch im Hinblick auf einen >großen < Kabinettskrieg jenes >Niemals! ${ }^{174}$ ausgesprochen hätte, das sein Nachfolger dann offiziell aus dem Wortschatz der modernen Diplomatie verbannte. Hübner, hellsichtig wie selten, fand den Schlüssel zu Napoleons Haltung: »Lors des conférences de Vienne, l'Empereur [...] désirait continuer la guerre, et c'est, par conséquent, dans un but de guerre qu'il recherchait alors l'alliance de l'Autriche. Aujourd'hui, il espère qu'elle l'aidera à faire la paix ${ }^{175}$. Z Zwar vermied der Kaiser, um London nicht kopfscheu zu machen, eine eindeutige und unwiderrufliche Weichenstellung ${ }^{176}$. Dennoch erkannte man an

wurden. Am 22. März war Pélissier von Vaillant angewiesen worden, die Einberufungsjahrgänge 1848,1849 und gegebenenfalls sogar $1850 \mathrm{zu}$ entlassen, vgl. SHAT (wie Anm. 5), G 1, 39, Nr. 23.

169 Vgl. Clarendon an Palmerston, 10. 3. 1856, AGKK, III, 4 (wie Anm. 1), Nr. 520.

170 Vgl. Clarendon an Granville, 12. 3. 1856, in: Herbert Maxwell, The Life and Letters of George William Frederick, Fourth Earl of Clarendon. Vol. 2, London 1913, S. 118 f.; Clarendon an Victoria, 30. 3. 1856, in: Victoria, Letters (wie Anm. 18), S. 184.

171. Vgl. Clarendon an Palmerston, 29. 2. 1856, in: Maxwell, Life (wie Anm. 170), S. 116 f.; Palmerston an Clarendon, 2. 3. 1856, AGKK, III, 4 (wie Anm. 1), S. 817, Anm. a.

172 "Sham conferences [...] pursuing a phantom of peace. "Clarendon an Cowley, 19. 11. 1855, AGKK, III, 4 (wie Anm. 1), Nr. 170.

173 Vgl. Drouyn de Lhuys an Bourqueney, 15. 1. 1855, in: Eugène de Guichen, La Guerre de Crimée 1854-1856 et l'attitude des puissances européennes, Paris 1936, S. 243 f.; Cowley an Clarendon, 14. 3. 1855, AGKK, Serie III, Bd 3: 3. 12. 1854 bis 9. 9. 1855. Bearb. von Winfried Baumgart unter Mitw. von Martin Senner, München 1994, Nr. 238; Hübner an Buol, 22. 3. 1855, AGKK, I, 2 (wie Anm. 57), Nr. 406; Drouyn de Lhuys an Napoleon, 8. 4. 1855, in: Bernard D'Harcourt, Les quatre ministères de M. Drouyn de Lhuys, Paris 1882, S. 135.

174 Vgl. Buol an Hübner, 29.11.1853, AGKK, Serie I, Bd 1: 27. 12. 1852 bis 25. 3. 1854. Bearb. von Ana María Schop Soler, München, Wien 1980, Nr. 247; Gramont an Drouyn de Lhuys, 26. 3. 1863, in: Problema Veneto (wie Anm. 29), vol. 3: Documenti diplomatici Francia. A cura di Georges Dethan, Venezia 1967, Nr. 270.

175 Hübner an Buol, 17. 12. 1855, AGKK, I, 3 (wie Anm. 7), Nr. 74.

176 "When he went to receive the Imperial Guard [...], some of his Ministers asked [...], what he intended to say? $>M a$ foi, he replied, je serai un peu belliqueux ! « Aberdeen an Gladstone, 16. 1. 1856, AGKK, III, 4 (wie Anm. 1), Nr. 354. 
der Themse schon Anfang Januar, daß die Signale aus den Tuilerien überwiegend keine kriegerischen waren ${ }^{177}$.

>A l'Anglaise،, zur Zurückdrängung Rußlands, von der Paris nicht unmittelbar profitieren würde, konnte Napoleon den Krieg aus innenpolitischen Gründen nicht führen; dies ‘à la Française zu tun, unter Proklamierung des Nationalitätenprinzips und zur Revision der französischen Grenzen, drohte »das große Resultat ${ }^{178}$ des Krimkriegs auf Spiel zu setzen. Statt Rußlands Nachfolge als Schiedsrichter Europas oder wenigstens Deutschlands ${ }^{179}$ antreten zu können, wäre Frankreich in jenen Teufelskreis aus außenpolitischer Isolation und innenpolitischer Labilität zurückgefallen, den es, Drouyn de Lhuys zufolge, zum ersten Mal "seit 70 Jahren ${ }^{180}$ durchbrochen hatte. Nicht daß der Kaiser deswegen auf seinen Wunschtraum, die >Umarbeitung der europäischen Landkarte, Verzicht geleistet hätte! Im Gegensatz zum Begründer seiner Dynastie war er aber mehr Fuchs denn Feldherr und hatte es sich zur Regel gemacht, "de ne pas marcher plus vite que les violons ${ }^{181}$. Er setzte, ein vorsichtiger Hasardeur, nicht auf die Karte des 'großen $<$ Krieges, sondern auf die des »großen Friedenscongresses « ${ }^{182}$. Wäre es ihm, und sei es im Sinne einer mittelfristigen Option, um den 'großen Krieg zu tun gewesen, den in Polen, dann hätte die ausbaufähige Bessarabien-Operation seine erste Wahl sein müssen. Er entschied sich indes für den skleinen < Krieg auf der Krim, obwohl dieser nicht zwingend notwendig war: Im Kriegsrat wurde »eine bloße Besetzung mit reduzierten Kräften ${ }^{183}$ durchaus als ernsthafte Alternative betrachtet. Auch Napoleons Reaktion auf die russischen Gegenvorschläge beweist, daß er weit entfernt war, die drohende Verwerfung des österreichischen Ultimatums als goldene Gelegenheit zur Ausweitung des Konflikts und Herbeiführung 'großer Territorialveränderungen ${ }^{184} \mathrm{zu}$ begreifen. Vielmehr verstand er den 18. Januar als Auftakt einer neuen Verhandlungsrunde mit Petersburg. Daß er militärische Drohgesten und sogar »einen entscheidenden Schlag ${ }{ }^{185}$ zur Beförderung des Friedenswerks keineswegs ausschloß, solange das diplomatische Spiel noch nicht eröffnet, geschweige denn gewonnen war, weist den Kaiser als Realpolitiker vom Schlage des gleichfalls lange verkannten Buol aus. Wie dieser ${ }^{186}$ handelte auch er nach der Devise: Si vis pacem, bellum para.

177 Vgl. Graham an Aberdeen, 2. 1. 1856, ebd., Nr. 305.

178 In Napoleons Worten: $\gg[$...] de mettre un terme à l'alliance des puissances contre la France. Avant ce changement, il n'eût pas été possible de réclamer le redressement d'aucun tort ni d'aucun grief sans provoquer contre nous une coalition." Aufzeichnung Foulds, 12. 3. 1856, AN (wie Anm. 3), 154 MI, 1.

179 Vgl. Persigny an Walewski, 19. 11. 1855, in: Guichen, Guerre (wie Anm. 173), S. 306; A. Damrémont an Walewski, 29. 2. 1856, AMAE (wie Anm. 10), CP Hesse-Darmstadt, 24, f. 79.

180 ,Letter [...] on M. Drouyn de Lhuys's opinions \& behaviours،, [August 1855], Oriental Question (wie Anm. 5), XVI, RA (M), G 37/67.

181 Napoleon an J. Napoleon, 22. 1. [!] 1863, in: Hauterive, Napoléon III. (wie Anm. 41), S. 238.

182 Ernst II., Aus meinem Leben (wie Anm. 39), S. 281 (zum 25. 9. 1855).

183 Gutachten Bosquets, 16. 1. 1856, PRO (wie Anm. 5), WO 33/2 B, S. 34; vgl. Gutachten J. Napoleons, 17. 1. 1856, AN (wie Anm. 3), 400 AP, 55, Nr. 2.

184 Denkschrift Napoleons, [Ende 1858], in: Olliver, L'Empire (wie Anm. 30), S. 538.

185 Napoleon an Persigny, 27. 1. 1856, Oriental Question (wie Anm. 5), XIX, RA (M), G $43 / 85$.

186 Vgl. Winfried Baumgart, Österreich und Preußen im Krimkrieg. Neue Forschungsergebnisse aufgrund der österreichischen Akten, in: Vorträge und Forschungen zur 
Der >kleiner, auf die Orientalische Frage beschränkte Kongreß, den er letztlich erhielt, war zumindest keine Illusion. Das unterschied ihn von dem auf die Abwicklung der Krim-Expedition zugeschnittenen >kleinen $<$ Krieg. Denn eher früher als später ersetzte Napoleon dann >kleinen` durch >keinen`, kam hinter der martialischen Maske ein fast bedingungsloser Friedenswille zum Vorschein $^{187}$. Frei nach Jean Giraudoux ${ }^{188}$; , La guerre de 1856 n'aura pas lieu.

Daß er weder als »Weltkrieg ${ }{ }^{189}$ noch überhaupt geführt wurde, konnte Alexander II. dem eigenen Realitätssinn und Buol der österreichischen Friedenspolitik zugute halten. Sie wäre allerdings ohne die entsprechenden Dispositionen auf französischer Seite genauso steril geblieben wie die Wiener Konferenzen.

Napoleon III. pflegte den ersten seines Namens gerne mit Julius Cäsar zu vergleichen. Sich selber sah er in der Rolle des Augustus, getreu seiner Parole, das Kaiserreich sei der Friede. Der mit Vorbedacht entfesselte Angriffskrieg von 1859, das leichtfertig begonnene mexikanische Abenteuer und das blutige Finale von 1870 haben sein Bild in der Geschichte freilich nachhaltig verdunkelt. Wie kaum eine andere militärische Aktion des Second Empire barg der Krimkrieg die Möglichkeit in sich, "Europa von Grund aus umzustürzen und es vielleicht in's Mittelalter zurückzuwerfen ${ }^{190}$. Der Kaiser hatte oft genug mit dem >Appell an die Nationalitäten ‘ gedroht ${ }^{191}$, um dessen für fähig gehalten $z u$ werden. Anfang 1856 jedoch widerstand er der durchaus gegebenen Versuchung ${ }^{192}$, eine weitere Runde auf dem Schlachtfeld zu wagen. Das darf ihm als historisches Verdienst gutgeschrieben werden, zumal er die Auffassung seines Außenministers, der bisherige Ertrag des Krieges übertreffe die kühnsten Erwartungen, im Grunde nicht teilte ${ }^{193}$. Gleichwohl machte er sie sich zu eigen - aus jener Kosten-Nutzen-Kalkulation ${ }^{194}$ heraus, die den Staatsmann vom Doktrinär unterscheidet.

preußisch-deutschen Geschichte. Hrsg. von Oswald Hauser, Köln, Wien 1983, S. 45-70, hier: S. 47-51.

187 "He wants to announce peace to France as a fait accompli \& he does not care 6 d about the conditions.« Clarendon an Palmerston, 23. 3. 1856, AGKK, III, 4 (wie Anm. 1), Nr. 565.

188 ,La guerre de Troie n'aura pas lieu (1935). - Die langwierige Belagerung Sevastopol's legte den Zeitgenossen die Metapher vom 'zweiten trojanischen Krieg nahe, vgl. Aufzeichnung Girauds, 4. 7. 1855, AN (wie Anm. 3), 400 AP, 128.

189 Neuf ans de souvenirs d'un ambassadeur d'Autriche à Paris sous le Second Empire 1851-1859. Publiés par son fils le comte Alexandre de Hübner. Vol. 1: 1851-1856, 3. éd., Paris 1905, S. 386 (zum 26. 1. 1856).

190 Grancÿ an Dalwigk, 13. 5. 1855, zit. nach Heinrich Euler, Napoleon III. Versuch einer Deutung, Miesbach 1972, S. 25.

191 Berühmtestes Beispiel: "''insurgerais l'Italie.« Hübner an Buol, 20. 11. 1853, Haus-, Hof und Staatsarchiv (HHStA), Wien, PA IX/43, f. 132.

192 Clarendon etwa brachte den Wunsch zum Ausdruck, Paris möge das Berliner Kabinett vor die Wahl stellen, »ou la paix obtenue [...] par une démonstration de toute l'Europe, ou une guerre continentale dont la Prusse sera le théâtre. [...] Comme c'est la France [...] qui est le plus intéressé $[. .$.$] , c'est aussi à elle à poser les termes de cette alternative",$ Persigny an Walewski, 2. 1. 1856, AMAE (wie Anm. 10), CP Angleterre, 704, f. 7 f. Zum Hintergrund vgl. AGKK, III, 4 (wie Anm. 1), S. 47 f. und die einschlägigen Quellen ebd.

193 »V. Majesté aura gagné tout ce que l'Empereur de Russie aura perdu, [...] le premier rang en Europe." Walewski an Napoleon, 11. 9. 1855, Familienarchiv Walewski, C 1, p. 27 f.; dagegen Napoleon an Viktor Emanuel, 5. 2. 1856, Il Carteggio Cavour-Nigra dal 1858 al 1861. A cura della commissione reale editrice [...]. Vol. 1: Plombières, Bologna 1926 [Neudr. 1961], Nr. 3: „Cette guerre était [...] peu profitable.«

194 Vgl. Napoleon an Victoria, 12. 4. 1856, in: Victoria, Letters (wie Anm. 18), S. 239 f.; ähn- 
Die Würfel fielen am 15. Januar, als der russische Autokrat seinen Kronrat, der französische Imperator seinen Conseil einberief. Beide Gremien, beide Herrscher kamen zu dem Schluß, den Waffengang zu beenden. Da für die Pariser Entscheidung, seine Weiterführung sei >unsinnig‘, jedoch bereits Rußlands Gegenvorschläge ausschlaggebend waren, hat das definitive Einlenken des Zaren den Friedensschluß nur mehr erleichtert. Ihn ermöglicht, die Fortsetzung des Krieges verhindert hat die Haltung Frankreichs. Denn England hätte, auf sich allein gestellt, nicht weiterkämpfen können, selbst wenn das Kabinett auf Palmerstons Kurs eingeschwenkt wäre ${ }^{195}$. Frankreich aber war gewillt, sich mit dem vor Sevastopol' erfochtenen Zuwachs an Waffenruhm und politischem Einfluß zufriedenzugeben. Insofern trifft der Kommentar eines französischen Diplomaten den Kern der Sache: "Jamais le mot de l'Empereur squand la France est satisfaite, l'Europe est tranquille - ne fut plus vrai ${ }^{196}$."

The British Lion smells a rat

(Punch, or The London Charivari, vol.30:1.1.-30.6. 1856, S. 105)

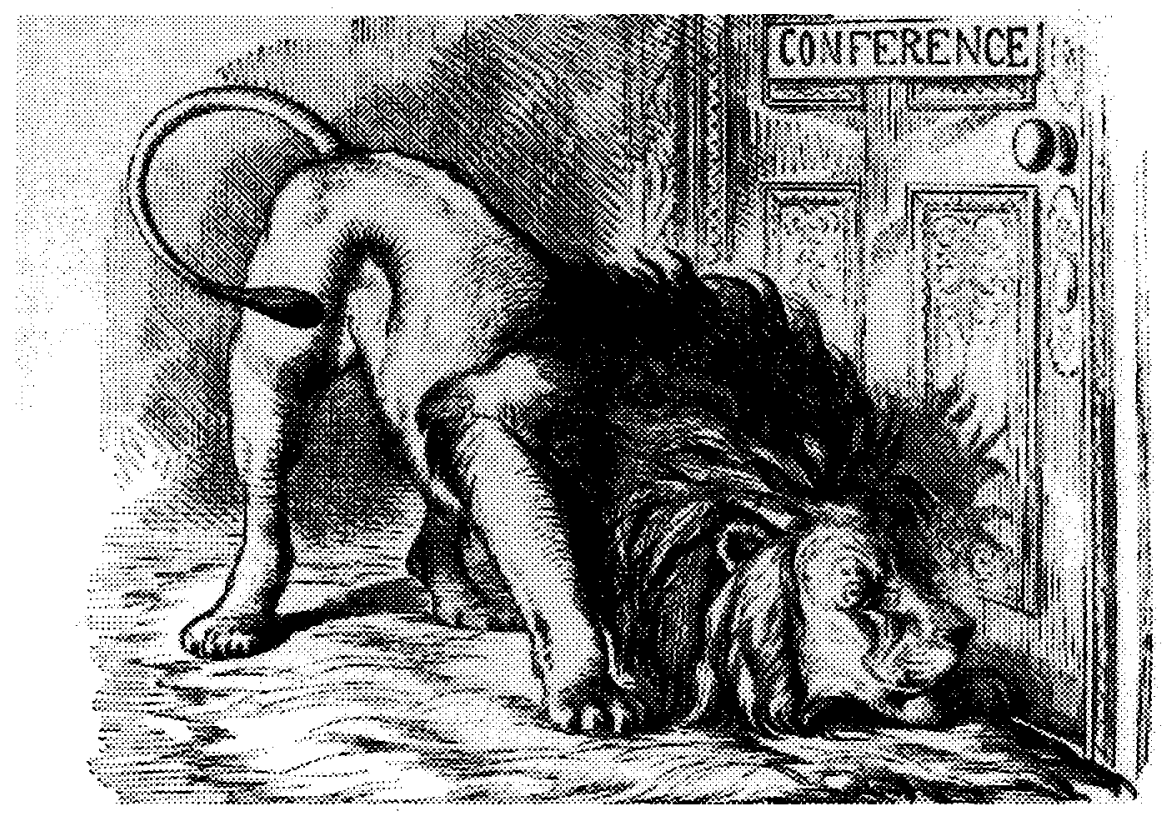

Diese Karikatur nahm zwar die Pariser Friedensverhandlungen aufs Korn, hätte aber ebensogut dem vorangegangenen, Kriegskongreßr gelten können

lich schon Napoleon an Ernst II., 11. 3. 1856, in: Ernst II., Aus meinem Leben (wie Anm. 39), S. $297 \mathrm{f}$.

195 Vgl. Colloredo an Buol, 13. 6. 1855, AGKK, I, 2 (wie Anm. 57), Nr. 487; Granville an Clarendon, 26. 11. 1855, AGKK, III, 4 (wie Anm. 1), Nr. 206; zum ganzen Baumgart, Friede (wie Anm. 4), S. 57-63 und AGKK, III, 4 (wie Anm. 1), S. 34.

196 Cintrat an Walewski, 23. 1. 1856, AMAE (wie Anm. 10), CP Hambourg, 154, f. 280. Das Zitat aus der Rede von Bordeaux (9. 10. 1852) lautet richtig: "Lorsque la France est satisfaite, le monde est tranquille.« OEuvres de Napoléon III. Vol. 3: 1848-1855, Paris 1869, S. 343 
